Traduções

Edição Especial da Revista Brasileira de História da Matemática - Vol. 18 n 36- pág. 31-75

Publicação Oficial da Sociedade Brasileira de História da Matemática

ISSN 1519-955X

\title{
EUCLIDES - SECTIO CANONIS - APRESENTAÇÃO E TRADUÇÃO
}

\author{
Gustavo Barbosa \\ Universidade Estadual Paulista “Júlio de Mesquita Filho” - UNESP - Brasil
}

(aceito para publicação em fevereiro de 2018)

\begin{abstract}
Resumo
O presente trabalho apresenta uma tradução do tratado musical de Euclides, a Sectio canonis. A tradução foi feita a partir da edição crítica de Karl von Jan, de 1895. Acompanha o texto uma apresentação da obra, problematizando o seu conteúdo e indicando como os comentadores de Euclides atribuem o primado de uma teoria musical ao pitagorismo. A partir dos textos de apoio são feitas notas de rodapé indicando a conexão da Sectio canonis com a principal obra de Euclides, Os Elementos.
\end{abstract}

Palavras-chave: Euclides, Harmonia, História, Matemática.

\section{[EUCLID - SECTIO CANONIS - PRESENTATION AND TRANSLATION]}

\begin{abstract}
The present paper presents a translation of the musical treatise of Euclides, the Sectio canonis. The translation was made from the critical edition of Karl von Jan, 1895. The text follows a presentation of the work, problematizing its content and indicating how Euclid's commentators attribute the primacy of a musical theory to Pythagoreanism. From the supporting texts are made footnotes indicating the connection of the Sectio canonis with the main work of Euclides, The Elements.
\end{abstract}

Keywords: Euclid, Harmony, History, Mathematics. 


\section{Apresentação}

Sectio canonis é o nome do tratado musical atribuído a Euclides. O seu programa é claro e simples: o estabelecimento de um sistema harmônico a partir de um conjunto de notas fundamentais. A obra representa a codificação do estudo da música na cultura grega antiga, e tornou-se paradigma para a pesquisa musical nos séculos seguintes. Sua importância para a História da Matemática é reconhecida e atestada por diversas razões, entre as quais destacamos:

i-) a formação dos conceitos musicais, como consonância e dissonância, entre outros. Com efeito, não é possível ignorar os componentes práticos da cultura arcaica, como os instrumentos de cordas, os de sopro e os de percussão. Sem perda de generalidade, podemos pensar na música como uma das manifestações mais antigas do ser humano. A favor disso, poder-se-ia argumentar que desde o útero materno temos um metrônomo batendo dentro de nosso peito. Note-se também que diferentes línguas possuem, além das palavras, toda uma sonoridade distinta. Por fim, há os pássaros, cujo canto parece representar um sopro das musas, inspirando infindáveis gerações de poetas e escritores. Por meio do intelecto a humanidade aperfeiçoou a fruição da audição, ao mesmo tempo em que o fez também com os outros sentidos. A visão, em especial, lidava com um céu repleto de astros em movimento, com uma natureza mutável, mas que obecedia a padrões de regularidade. Disso parece emergir um interesse matemático, que em algum momento perdido no tempo e no espaço, voltou-se para a atividade musical. Assim, os eventos acústicos foram simplificados e modelados segundo certas relações aritmo-geométricas. Os sons, inicialmente classificados agradáveis ou desagradáveis aos ouvidos, foram imbricados a uma justificação racional de assim o serem. Iniciava-se, de tal modo, o que a língua grega descreve como um método - termo composto pelo substantivo hodos, que significa "caminho", e a preposição meta, significando, neste caso, "com", "em companhia de". Esse caminho culminou em uma teoria, em que o modelo aritmo-geométrico passou a ser a referência primeira para o estudo dos acordes conhecidos e para a obtenção de outros. Os sons, subsumidos à matemática, passaram a ser regidos por ela. Deve-se, contudo, observar que essa tradução da música para uma linguagem matemática não substitui os fatos aceitos pela experiência, mas depende crucialmente das considerações físicas feitas no início do texto da Sectio canonis. A preocupação do autor em fornecer provas sistemáticas e formais das proposições indica o grau de maturidade científica a que a harmonia grega havia chegado em meados do século III antes da Era Comum. Algo que vai além do âmbito puramente matemático, e que aponta para um programa filosófico, como veremos a seguir.

ii-) entremeada ao item anterior está a herança pitagórica que a Sectio canonis representa. Já bem conhecida pela filosofia, uma vez que se encontra nas obras de Platão e Aristóteles, a symphonia de que trata Euclides vem da tradição pitagórica. A doutrina de Pitágoras e seus seguidores representou um esforço primordial de modelagem dos eventos acústicos que acompanhavam canções, rituais, poemas e o teatro. Ao compilar os conhecimentos musicais acumulados até então, Euclides os homogeneiza, ou aplaina, segundo a matemática também compilada nos Elementos. Ao abrir uma dessas obras, o historiador da 
matemática assemelha-se a um arqueólogo parado em pé sobre uma planície, imaginando o que poderá encontrar ao escavar aquele local. Como primeira referência estão autores posteriores a Euclides, que comentaram a sua obra, como Cláudio Ptolomeu (aprox. 85 aprox. 165 EC), Porfírio (aprox. 234 - aprox. 305 EC) e Téon de Esmirna (aprox. 70 aprox. 135 EC). Estes, por sua vez, apontam para os extratos fósseis dos chamados PréSocráticos; os três autores acima referidos imputam a Arquitas de Tarento (aprox. 428 350 aprox. aEC) o primado de uma teoria musical fundada sobre base matemática. Então, é preciso debruçar-se sobre o que este pensador teria escrito (escavando novamente, até a filosofia que ele próprio utiliza como base), mas também esboçar um quadro do que foi dito a respeito dele por outros. Tido como "o mais distinto" pitagórico no tempo de Platão (KAHN, 2007, p. 61), Arquitas influenciou o filósofo ateniense, considerado seu amigo. Vários trechos matemáticos dos diálogos de Platão são colocados em relação com a atividade científica de Arquitas. Para se ter uma ideia, um ramo do platonismo interroga-se em qual medida a imagem de Arquitas como estadista, general e cientista inspirou a filosofia e os escritos de Platão. A República e o Timeu talvez sejam os exemplos de maior destaque. Ao lado de sua importância nos acontecimentos culturais de seu próprio tempo, está a compreensão de Arquitas como mais um veio nas águas agitadas do pitagorismo. "Podemos reconhecer o rigor e a clareza da teoria harmônica de Arquitas como uma obra de gênio original, mas este era um gênio que trabalhava na tradição musical pitagórica, que é representada para nós pela teoria inicial de Filolau"1. Como se vê, é possível remeter a teoria contida na Sectio canonis até suas origens pitagóricas, seja àquela reinterpretada na Academia, seja à mais arcaica e primordial. Não é o nosso propósito levar essa tarefa a cabo aqui, para nós basta conscientizar o leitor de que entre as páginas e proposições da Sectio canonis esconde-se uma história bela e envolvente.

\section{A introdução da Sectio canonis}

$\mathrm{O}$ argumento inicial diz respeito a natureza física dos sons, que são produzidos por meio de movimentos e percussão. Os sons com frequência maior dão origem às notas agudas; os com frequência menor, às graves. As notas agudas, que são compostas de movimentos mais frequentes e numerosos, tornam-se mais graves quando afrouxadas. Do mesmo modo, as notas graves, que são compostas de movimentos menos frequentes e numerosos, tornam-se agudas quando retesadas. A imagem de um músico soltando ou apertando a tarraxa de seu instrumento de cordas é um auxílio bem-vindo aqui. A este processo Euclides identifica uma subtração e uma soma de movimento, respectivamente. Logo, essa variação quantitativa (movimento, frequência) que acompanha a variação qualitativa (agudo e grave) é interpretada como uma composição por partes. E para Euclides, tudo o que é composto por partes pode ser colocado em relação com uma proporção numérica. Assim, o autor passa do estudo físico dos sons para a sua representação matemática, classificando as notas de acordo com a relação entre elas em tais proporções. Por fim, o autor estabelece como consonantes as notas que fazem uma única combinação de som. A interpretação física moderna desse fato é que a combinação se deve ao fato de as frequências se sobreporem,

${ }^{1}$ Id., p. 65.

RBHM, Vol. 18, n 36, p. 31-75, 2018 
soando aos ouvidos como uma única nota. Fato este que pode ser facilmente aferido pela experiência. As notas dissonantes são aquelas onde isso não ocorre, criando um som discordante.

\section{Acerca do cânone}

O que em geral designamos pela palavra cânone (norma, preceito, modelo, padrão) deriva do grego kanon, originariamente uma régua ou barra utilizada para averiguar ou preservar retidão, o uso do termo é também atestado na astronomia ${ }^{2}$. Os pitagóricos chamavam kanonike a arte ou ciência (techne) da retidão, com base no que a razão (logos) considera correto e bem sintonizado (BARKER, 2004, p. 239-240). O seu praticante, o kanonikos era um teórico harmônico cujo ofício era a construção de razões em sintonia. O nome transferiu-se ao instrumento utilizado para esse fim. Portanto, o kanon passou a designar o instrumento constituído por uma única corda estendida por entre dois pontos fixos, sobre uma base rígida. Também conhecido por monocórdio, era ainda composto por: uma base móvel que permitia alterar o comprimento da corda, e o som produzido por ela; e uma régua ou escala fixa, em que eram indicadas as posições das notas. Mais uma vez, a palavra kanon transferiu-se, por metonímia, primeiro para a escala, e depois para a sua representação abstrata como um segmento de reta. Isto posto, chegamos ao que Euclides chama de Divisão do cânone, isto é, a segmentação aritmo-geométrica da representação da escala musical em proporções.

\section{Acerca da divisão}

Uma vez fixada a corda do cânone na extremidade móvel, obtinha-se um determinado som - uma nota - que encontrava um segmento correspondente na escala. A divisão primordial seguia um modelo pitagórico, pois valia-se da tetraktys, a saber, o conjunto formado pela unidade e pelos três primeiros números $(1,2,3,4)$, cuja soma resulta no número dez. De acordo com o que nos transmitiu Aristóteles, na Metafísica (A 5, 986a8-9), na concepção pitagórica "o número dez parece ser perfeito e parece compreender em si toda a realidade dos números" (ARISTÓTELES, 2002, p. 27).

Por meio dos elementos da tetraktys geram-se os intervalos fundamentais:

i. $\quad$ a oitava, que corresponde à relação $2: 1$;

ii. a quinta, que corresponde à relação $3: 2$;

iii. e a quarta, que corresponde à relação $4: 3$.

\section{O cálculo dos intervalos}

Grosso modo, a harmonia grega é o estudo das relações entre intervalos e do que é possível obter compondo-os. Isso é feito de acordo com as operações estabelecidas. Ao passo que se

\footnotetext{
${ }^{2}$ Ver LIDDELL; SCOTT, 1940. In:

http://www.perseus.tufts.edu/hopper/text?doc=Perseus\%3Atext\%3A1999.04.0057\%3Aentry=kanw\%2Fn
} 
utiliza uma linguagem aditiva ou subtrativa, as operações efetuadas são a multiplicação ou a divisão. Por exemplo: o tom é definido como a diferença entre a quinta e a quarta, o que é representado em linguagem moderna como $(3: 2) \div(4: 3)=9: 8$. Os mesmos intervalos quando compostos formam a oitava, ou seja: $(3: 2) \times(4: 3)=2: 1$. E uma forma alternativa de se obter a oitava é pela composição de duas quartas intercaladas por um tom: $(4: 3) \times(9: 8) \times(4: 3)=2: 1$.

\section{A classificação dos intervalos}

Na introdução da Sectio canonis, Euclides associa os intervalos musicais a três relações numéricas, em que o termo maior precede sempre o menor. São elas:

i-) múltipla (pollaplasion), onde o termo menor é uma parte do maior ${ }^{3}$, representada como $n: 1, \operatorname{com} n>1$;

ii-) superparticular (epimorion), em que os termos diferem por uma unidade, representada como $n+1: n, \operatorname{com} n>1$;

iii-) superdividida (epimeres), em que o excesso do termo maior é "partes" do menor, isto é, a diferença entre o maior e o menor não divide este ${ }^{4}$, representada como $n+m: n$, com $n>m>1$.

Algumas relações são múltiplas ou superparticulares, e obedecem a intervalos específicos: a oitava é chamada um intervalo duplo; a quinta, um "hemiólico"; a quarta, um “epítrito”; e o tom, um “epogdóico”. Com excessão do adjetivo grego hemiolios, que tem correspondente em língua portuguesa como sesquiáltero, os outros termos usados acima entre aspas não têm equivalente no português. Os autores das traduções por nós cotejadas valem-se da transliteração, e, de nossa parte, seguimos o mesmo processo. Vale destacar os significados daquelas palavras: sobre sesquiáltero, o dicionário nos faz saber que "diz-se de duas quantidades das quais uma contém a outra vez e meia"5. O que é expresso pelo intervalo de quinta, $3: 2$. Do mesmo modo, epitritos significa, em grego, o que "contém um inteiro e um terço $(1+1 / 3)$ ", , e, portanto, o intervalo de quarta, (4 : 3). Por fim, epogdoos exprime o que contém um inteiro mais um oitavo $(1+1 / 8)$, no caso, o tom, ( $9: 8)$. Cabe ao leitor, para um melhor proveito na leitura da Sectio canonis, ter em mente as respectivas relações quando encontrar tais palavras ao longo do texto.

\section{Das proposições}

\footnotetext{
${ }^{3}$ Ver Elementos, VII, Def. 3.

${ }^{4}$ Ver Elementos, VII, Def. 4.

${ }^{5}$ Ver Dicionário Priberam da Língua Portuguesa. In: https://www.priberam.pt/dlpo/sesqui\%C3\%A1ltero.

${ }^{6}$ Ver LIDDELL; SCOTT, 1940. In: http://www.perseus.tufts.edu/hopper/morph?l=epitritos\&la=greek - lexicon.
}

RBHM, Vol. 18, n 36, p. 31-75, 2018 
Após a introdução seguem-se vinte proposições, das quais as nove primeiras derivam da teoria euclidiana dos números. Nelas são demonstradas propriedades a partir dos intervalos fundamentais, e o seu entendimento depende de resultados estabelecidos nos Elementos, como mostram as notas de rodapé. Somente na décima proposição é que os conceitos estritamente musicais são introduzidos. As quatro primeiras (10-13) identificam os intervalos musicais fundamentais (oitava, quarta, quinta e o tom) com as relações correspondentes. As três proposições seguintes (14-16) provam desigualdades imediatamente derivadas das precedentes. As proposições 17 e 18 mostram como localizar certas notas não harmônicas e as duas últimas possuem natureza geométrico construtiva. Por meio de divisões sucessivas são determinadas as notas fixas (19), e depois as móveis (20).

\section{A edição de referência, os textos de apoio e a tradução}

Segundo Acerbi (2008, p. 691), dos 33 manuscritos em que é atestada a Sectio canonis, 21 o atribuem a Euclides, 11 são anônimos, e a versão contida no documento Vat. Gr, 191 não possui qualquer indicação de autor ${ }^{7}$. O primeiro editor crítico da obra, Karl Jan, propôs que a Sectio canonis fosse um compêndio de uma obra mais ampla ${ }^{8}$.

Ptolomeu, na qualidade de intérprete mais próximo de Euclides, apresenta em sua própria obra (Harmonica I.5) o princípio de consonância estabelecido na introdução da Sectio canonis. Citando os "líderes da escola Pitagórica", o nome de Euclides não vem mencionado, não obstante Ptolomeu retome resultados encontrados na Sectio canonis.

Porfírio, que viveu menos de um século após Ptolomeu, ao comentar a obra deste, faz a associação explícita com a Sectio canonis. Porfírio observa ainda que diferentemente dos Elementos, onde Euclides recorre ao termo logos, na Sectio canonis o mesmo não aparece, sendo substituído por diastema (alternativo para razão, mas também intervalo).

A tradução trazida aqui a lume foi feita a partir do texto grego de Karl Jan (JANUS, 1895), e cotejada com outras três diferentes traduções: a de Barker (2004); a de Acerbi (2008); e a de Domené (2016), cada uma em uma língua diferente: inglês, italiano e espanhol, respectivamente. Tanto a primeira, quanto a última obra referida traz as traduções dos textos de outros autores importantes para a história da musica, como Ptolomeu e Porfírio; ao passo que a obra de Acerbi é restrita a Euclides, e talvez represente o trabalho mais completo em volume único sobre este obscuro personagem da história da matemática.

Não poderíamos deixar de manifestar aqui o nosso débito para com a versão brasileira dos Elementos (EUCLIDES, 2009), bem como para com seu tradutor, o Prof. Dr. Irineu Bicudo. Em primeiro lugar, mencionamos as muitas semelhanças entre o texto da Sectio canonis e dos Elementos, desde a estrutura da redação das proposições, ao modo como Euclides relaciona os termos. Como explicamos no parágrafo acima, o entendimento de grande parte da Sectio canonis depende da matemática determinada nos Elementos. Tendo, pois, à disposição uma obra já traduzida do antigo autor, a conversão de outras tem as dificuldades atenuadas. É sempre mais fácil seguir o caminho já aberto por um

\footnotetext{
${ }^{7}$ Esta versão pode ser verificada em: https://digi.vatlib.it/view/MSS Vat.gr.191 .

${ }^{8}$ Id., p. 692.
} 
desbravador do que fazê-lo por meio dos próprios esforços, a menos que se queira afastarse de tais escolhas prévias, o que com certeza não foi o caso aqui. Pelo contrário, nossas decisões foram pautadas tomando-se como base a tradução dos Elementos, onde é estabelecido o estilo da escrita da matemática grega. Uma vez feita a difícil tarefa de escolha e negociação por seu tradutor, coube a nós nos aproximarmos do mesmo estilo, sempre que possível. Em segundo lugar, agradecemos pelos aprendizados obtidos das línguas grega e latina junto ao Prof. Irineu, que com paciência e persistência vem transmitindo os seus conhecimentos a um pequeno, mas assíduo grupo de interessados.

Por fim, como preferimos ser óbvios a herméticos, declaramos que os todos os erros e imperfeições contidas na tradução da Sectio canonis a seguir são de responsabilidade única de seu tradutor.

Esperamos que o leitor faça um bom proveito.

\section{Bibliografia}

ACERBI, Fabio. 2008. Euclide. Tutte le opere, Milano, Il edizione Bompiani.

ARISTÓTELES. 2002. Metafísica. Volume II: texto grego com tradução ao lado, São Paulo, Edições Loyola.

BARKER, Andrew. 2004. Greek Musical Writings. Volume II: Harmonics amd Acoustic Theory, Cambridge, CUP.

DOMENÉ, Fuensanta Garrido. 2016. Los teóricos menores de la música griega. Euclides el Geómetra, Nicómaco de Gerasa y Gaudencio el Filósofo, Barcelona, Editorial Cérix.

EUCLIDES. 2009. Os Elementos. Tradução e introdução de Irineu Bicudo. São Paulo, Editora UNESP.

JANUS, Carolus (Karl von Jan). 1895. Musici Scriptores Graeci: Aristoteles, Euclides, Nicomachus, Bacchius, Gaudentius, Alypius Et Melodiarum Veterum Quidquid Exstat, Leipzig, B. G. Teubner.

KAHN, Charles. 2007. Pitágoras e os Pitagóricos - uma breve história, São Paulo, Edições Loyola.

\section{Gustavo Barbosa}

Departamento de Educação Matemática - UNESP campus de Rio Claro - Brasil

E-mail: gvbarbosa@gmail.com 


\section{ETK $\Lambda E I \Delta O T$}

\section{$K \alpha \tau \alpha \tau \circ \mu \eta \dot{\eta} \times \alpha \nu$ óvos.}

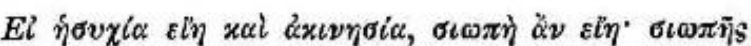

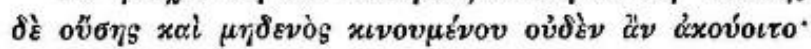

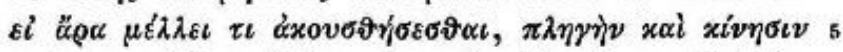

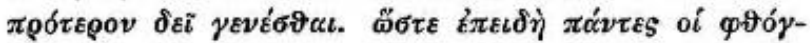

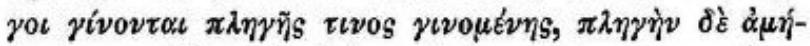

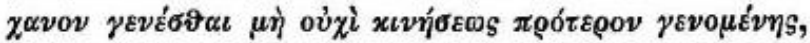

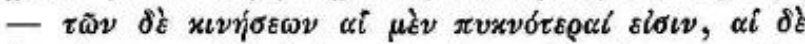

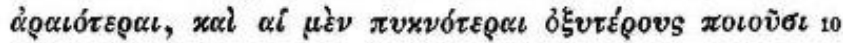

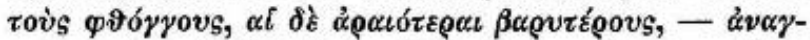

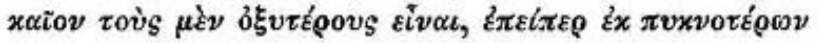

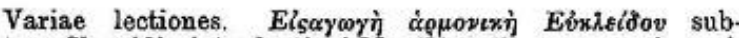

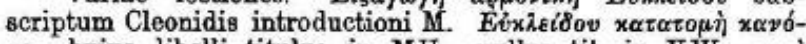
vos huius libelli titulus in $\mathrm{MU}$. nullus tit. in $V \mathrm{~W}$. $\pi$ eq

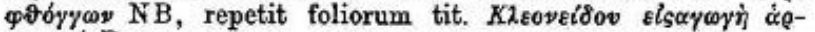

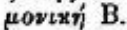

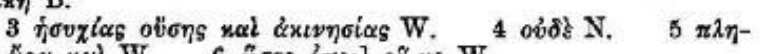

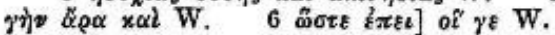

Ad prooemium of. commentarium Ps.-Porphyri in Ptolemaei harmonica p. 266 et Adrastum apud Theonem de musica c. 6 (p. 50). 


\section{Tradução}

\section{EUCLIDES}

Divisão do cânone.

Se houvesse quietude e imobilidade, então haveria silêncio: e havendo silêncio, e nada se movendo, então nada seria ouvido: se, portanto, alguma coisa está para ser ouvida, é preciso que antes ocorram impacto e movimento. De modo que todas as notas ocorrem quando ocorre um impacto, de modo que é impossível ocorrer um impacto sem que ocorra antes um movimento, - e dos movimentos, uns são os mais frequentes, outros os mais intermitentes; os mais frequentes produzem as notas agudas, e os intermitentes, as graves, - e é necessário que algumas $<$ notas> sejam agudas, visto que são compostas de 


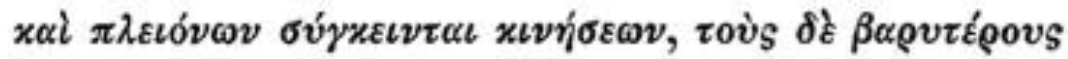

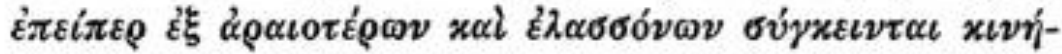

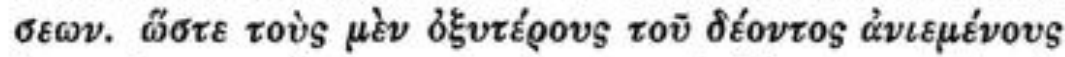

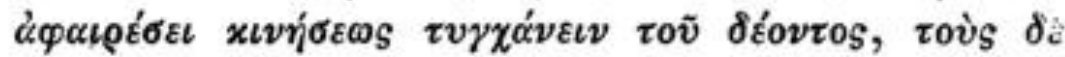

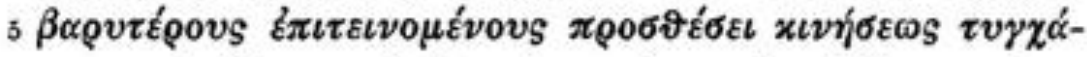

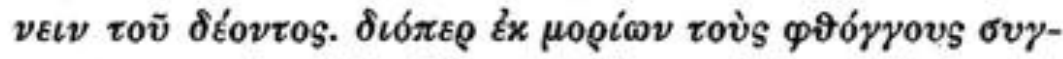

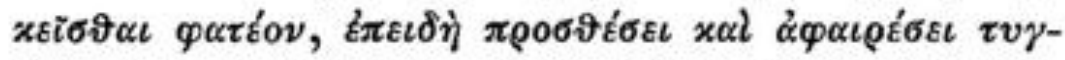

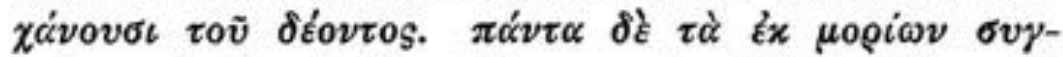

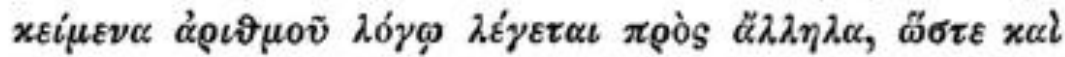

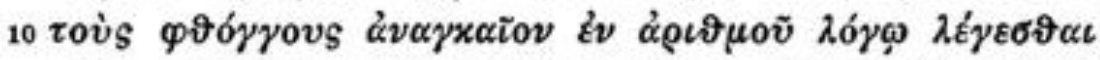

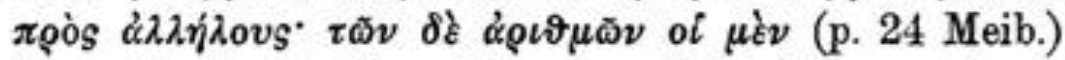

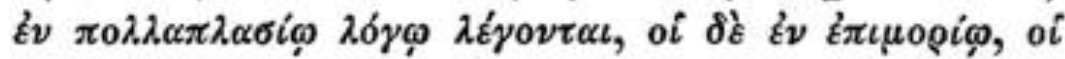

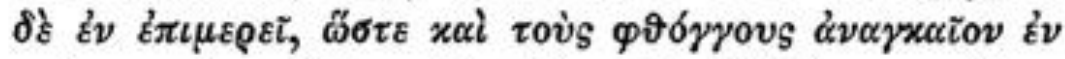

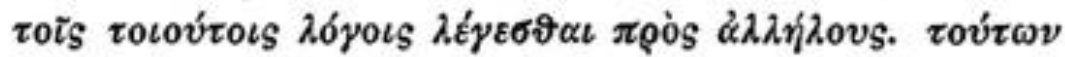

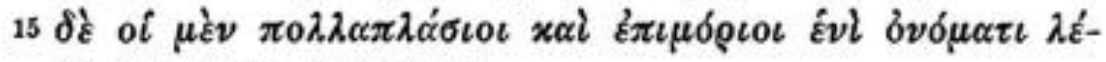

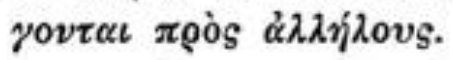

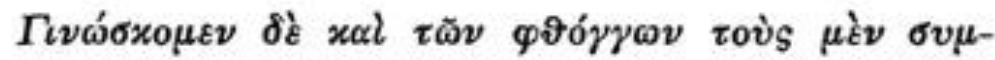

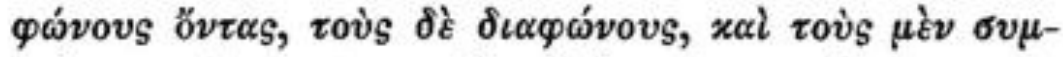

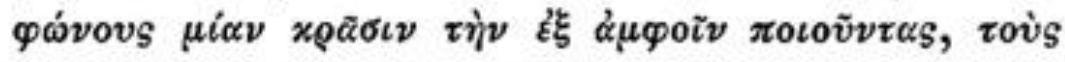

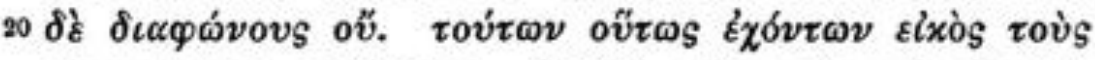

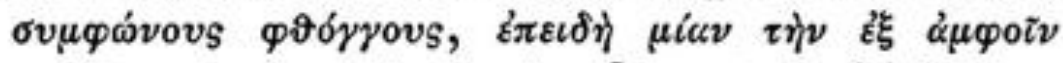

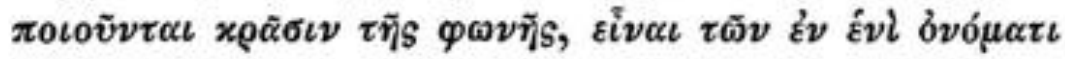

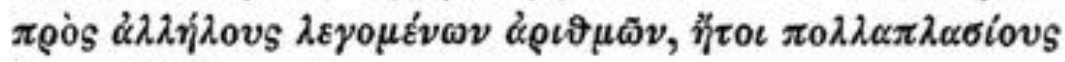

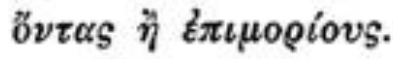

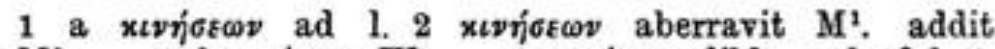

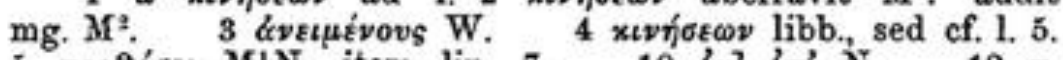

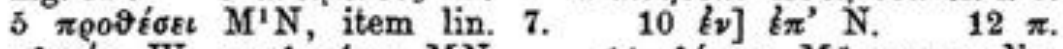
$\pi \lambda \alpha \sigma i \omega \mathrm{W}, \pi . \pi \lambda \alpha \sigma i o \nu i \mathrm{MN} .14$ 2.6yous $\mathrm{M}^{2}$ supra lin. 18 post

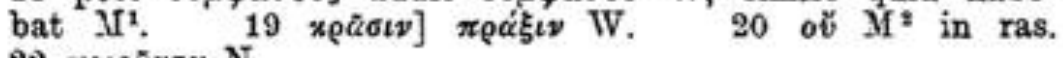

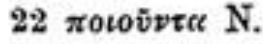


movimentos mais frequentes e numerosos, e outras graves, visto que são compostas de movimentos mais intermitentes e menos numerosos. De modo que as mais agudas que o preciso, por um lado, afrouxam pela subtração de movimento, atingindo o que é preciso; as mais graves, por outro lado, se estendem por soma de movimento, atingindo o que é preciso. Por isso, deve-se dizer que as notas se compõem de partes, uma vez que pela soma ou subtração obtêm-se o que é preciso. E todas as coisas que são compostas de partes se dizem em relação numérica recíproca, de modo que é necessário também às notas estarem em relação numérica recíproca. E dos números, alguns se dizem em relação múltipla, outros em superparticular, outros em superdividida, de modo que é necessário também às notas estarem em tais relações. E destas, as múltiplas e superparticulares se dizem em relação com um só nome.

E sabemos também que das notas, algumas são consonantes, outras dissonantes, e as consonantes, por um lado, fazem uma única combinação de ambas, as dissonantes, por outro lado, não. Em vista disso, é razoável que as notas consonantes, uma vez que fazem uma única combinação de som, estejam entre os números que se dizem em relação recíproca com um só nome, ou múltiplos ou superparticulares. 


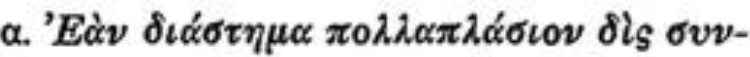

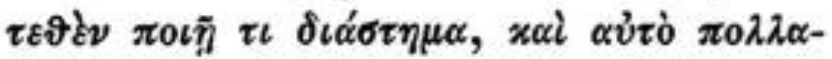
$\pi \lambda \alpha \dot{\sigma} \sigma \nu \nu$ ह̈ $\sigma \tau \alpha$.

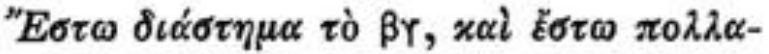

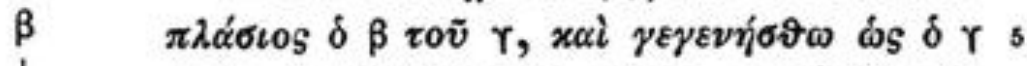

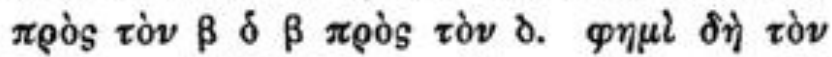

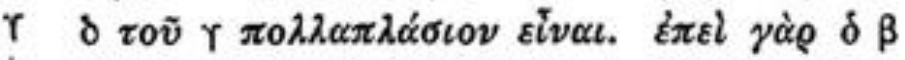

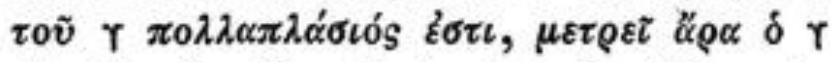

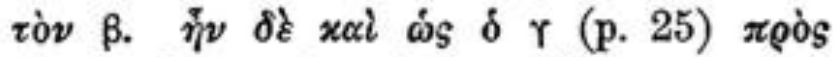

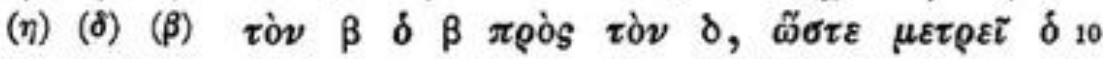

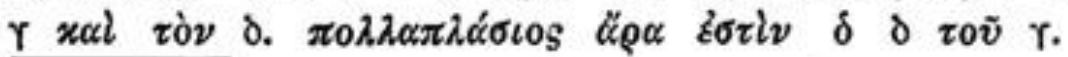

1 Hinc quae sequuntur ad p. 161, 14. 15 leguntur etiam apud Porphyrium vel potius auctorem commentarii ad Ptolemaei harmonica (Prol. p. 116 ann. 1) p. $272 \mathrm{ss.}$

Numeros quibus singulae protases distinguantur omittunt $\mathrm{M}^{1} \mathrm{~W}$, asteriscis et numeris Graecis $\alpha \beta$ notant $\mathrm{M}^{2} \mathrm{~V}$, Arabum numeros 12 ascribit $\mathrm{N}$.

Diagrammatum veterum lineis ad horizontem directis neglegenter pictorum (qualia vides ad prot. 2) exigua exstant vestigia in MW p. $151,1-3.152,7.11 .153,5.154,7.158,7$, quae reiecta esse solent ad posteriores protases. - Novas ascripsit figuras $\mathrm{M}^{2}$ marg., quorum lineae ad perpendiculum sunt directae (v. fig. 1. 3 sqq.). neglecta tamen $M^{x} V$ vera longitudine lineas omnes exaequaverunt, diligentius veram linearum mensuram observant $\mathrm{N}$ et Par. 2535, diligentius etiam Barb. II 86, id quod Euclidis sententia intellecta fieri facile potuit. recta haec linearum mensura cum ad voluntatem Euclidis cognoscendam videretur necessaria, ego in illis delineandis recentiorum codicum rationem amplexus sum; si quid praeter longitudinem in $\mathrm{M}^{2}$ discrepabat. semper notavi. rettulit autem $\mathrm{N}$ diagrammata in locos iusto superiores, ut fig. 15 inveniatur apud prot. 8. - Exstat hoc diagramma suo loco in $\mathrm{M}^{2} \mathrm{mg}$., VU, (de NPB qui ad duas protases demonstrandas uno utuntur diagrammate vide infra). aliud habent diagramma una linea ad horizontem porrecta numerisque 4816 signata $\mathrm{M}^{1} \mathrm{~W}$ inter verba prot. 2 . quo enim quaeque sit revocanda figura, clare elucet e quattuor lineis diagrammatis 3 .

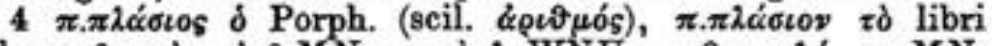

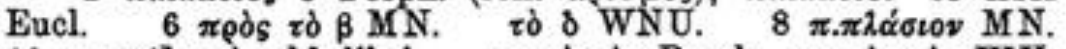

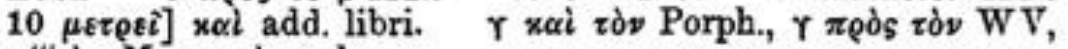
$\gamma / / / \tau \dot{\nu} \nu$ M. $\gamma \tau \dot{\tau} \nu$ rel. 
$\delta$

$\mid$

(8) (4) (2)
1. Caso um intervalo 9 múltiplo duas vezes composto faça um intervalo, este será também múltiplo.

Seja o $\beta \gamma$ um intervalo, e seja o $\beta$ múltiplo de $\gamma$, e fique posto, assim como o $\gamma$ para o $\beta$, o $\beta$ para o $\delta$. Digo então que o $\delta$ é múltiplo de $\gamma$. Pois, como o $\beta$ é múltiplo de $\gamma$, o $\gamma$, portanto, mede o $\beta$. E como o $\gamma \gamma$ estava para o $\beta$, o $\beta$ está para o $\delta$, de modo que o $\gamma$ também mede o $\delta$. Portanto, o $\delta$ é múltiplo de $\gamma$.

${ }^{9} \mathrm{O}$ termo intervalo (diastema) possui aqui conotação mais ampla do que a estritamente musical, sendo aplicado de modo indistinto à relação entre duas magnitudes quaisquer (que podem ser segmentos ou números), uma vez que a palavra tem o significado geral de "distância" ou "separação". Cf. Barker, 2004, p. 194, n. 9.

RBHM, Vol. 18, nº 36, p. 31-75, 2018 


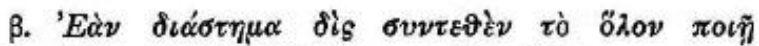

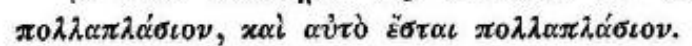

$$
\frac{r}{5}+\frac{\beta}{\iota p}+\frac{\delta}{x \delta}
$$

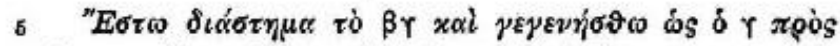

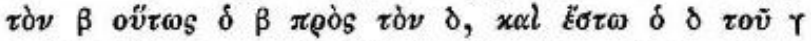

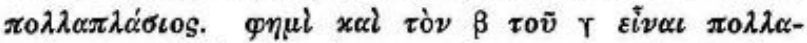

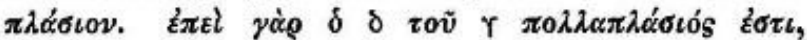

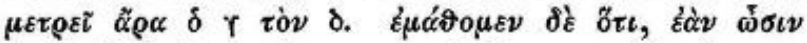

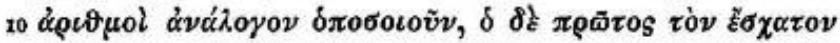

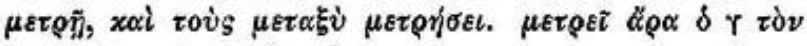

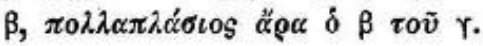

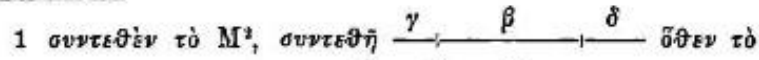

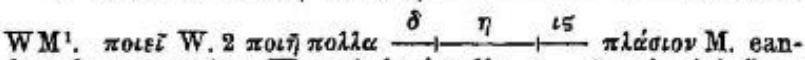

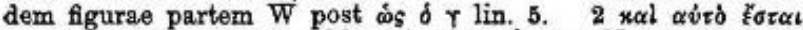

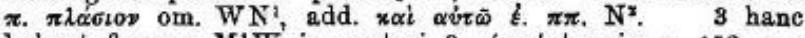
habent figuram $M^{1} W$ in protasi 3 . (exstat enim p. 152, 1-2

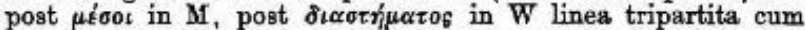

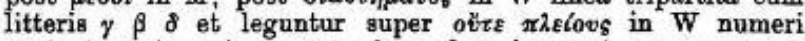
$5 \iota \beta$ et post $\pi \lambda$ siovs num. $x \delta$, eosdem inserunt numeros post $\pi \lambda$ Elovs $\mathrm{V} \mathrm{U}$. in $\mathrm{M} u \dot{\omega} \sigma o t$ in ras., post $\pi \lambda_{\varepsilon}$ lovs rasura. ad illam autem protasin longe alia opus erat figura.) simile diagramma atque ad prot. $1 \mathrm{M}^{2}$. numeri tamen $15 \eta \delta$. hanc figuram cum numeris $\delta \eta$ is ad prot, 1 rettulerunt NPB, qui ad 2 dant fig. 3. $\quad 7 \quad \varphi \eta \mu l \quad \delta \eta \mathrm{MI}^{4}, \quad 8 \pi \pi . \quad \varphi \eta \mu i^{\prime}$ lortv $\mathrm{N}^{1}$

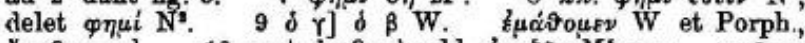

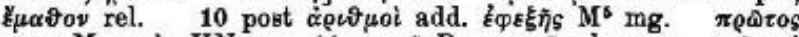

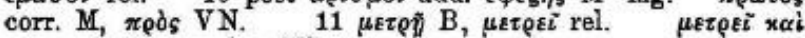

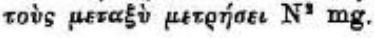

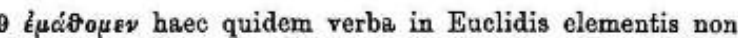
inveniuntur (cf. Heiberg, litterargeach. Studien über Euklid,

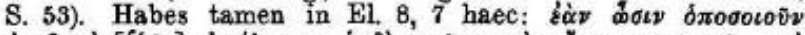

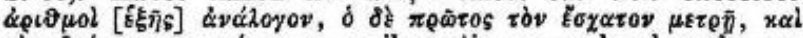

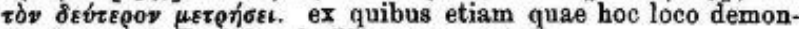
straturus est Euclides facillime sequuntur. 


\section{Caso um intervalo duas vezes composto faça um todo múltiplo, este também será múltiplo.}

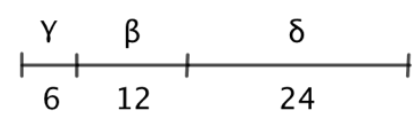

Seja o $\beta \gamma$ um intervalo, e fique posto, assim como o $\gamma$ para o $\beta$, do mesmo modo o $\beta$ para o $\delta$, e seja o $\delta$ múltiplo de $\gamma$ : digo que o $\beta$ também é múltiplo de $\gamma$. Pois, como o $\delta$ é múltiplo de $\gamma$, o $\gamma$, portanto, mede o $\delta$. $\mathrm{E}$ aprendemos ${ }^{10}$ que caso números, em uma quantidade qualquer, estejam em proporção, e o primeiro meça o último, medirá também os do meio. Portanto, o $\gamma$ mede o $\beta$, e o $\beta$ é, portanto, múltiplo de $\gamma$.

${ }^{10}$ A referência é aos Elementos VIII. 7, onde o enunciado da proposição é muito semelhante ao da Sectio canonis. Cf. Barker, 2004, p. 194, n. 11.

RBHM, Vol. 18, nº 36, p. 31-75, 2018 


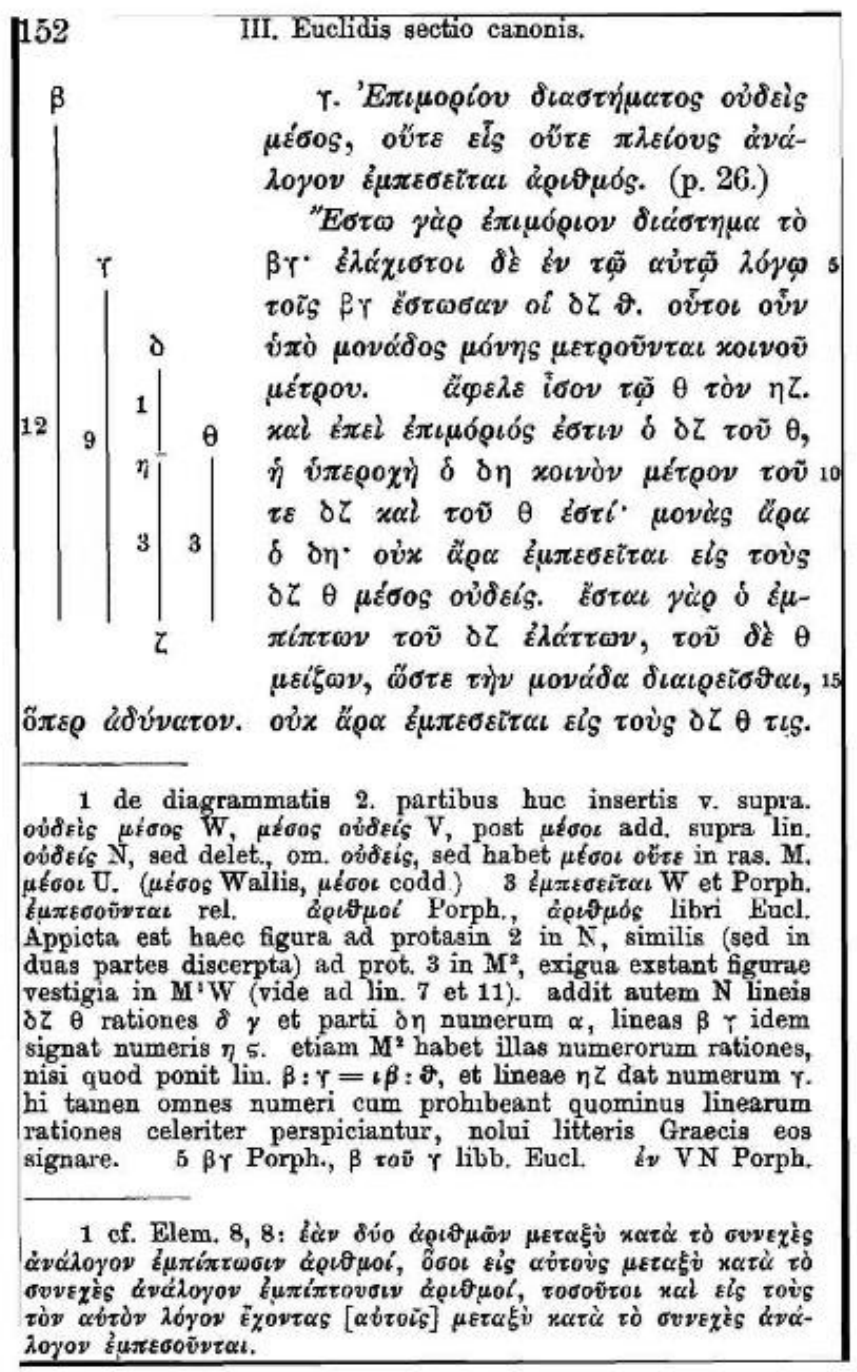




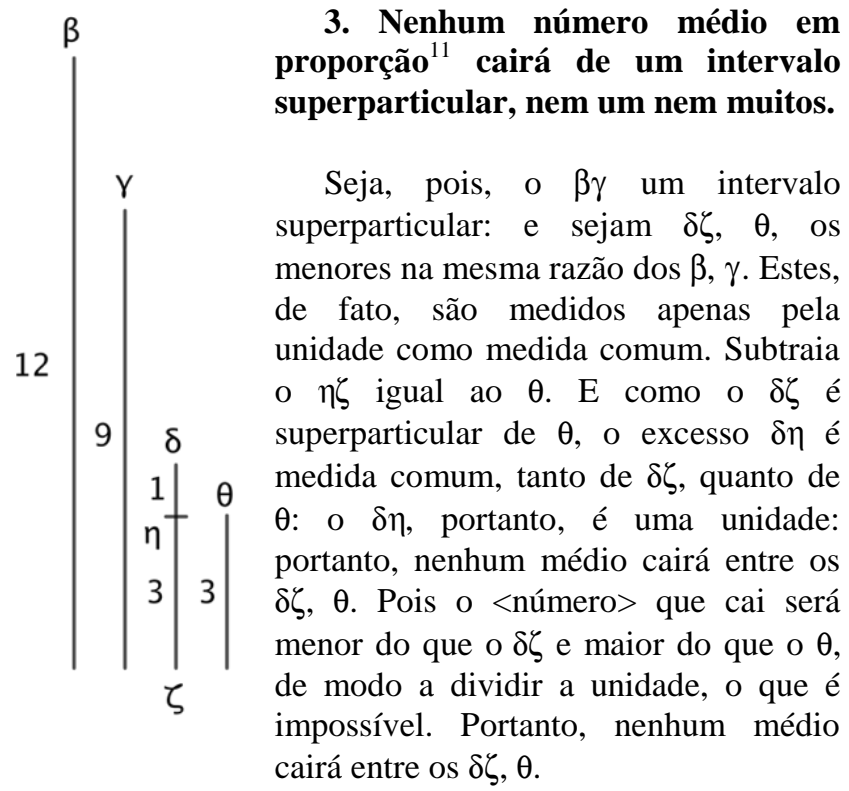

${ }^{11}$ A despeito dessa relação, ver Elementos VIII. 11, 12. 


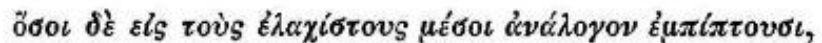

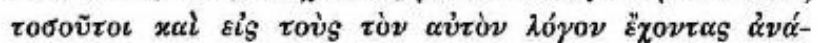

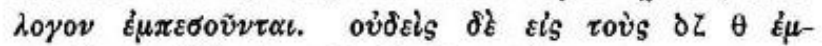

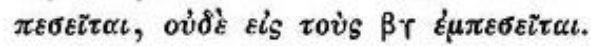

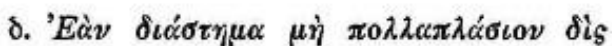

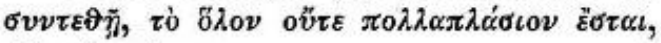

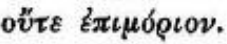

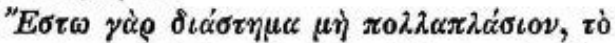

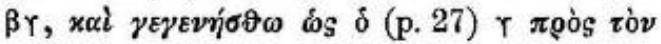

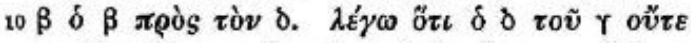

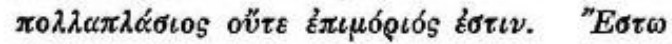

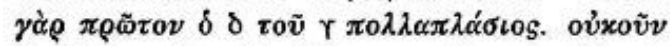

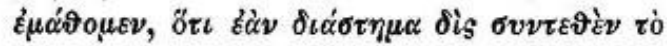

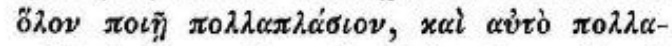

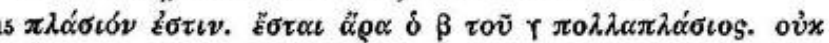

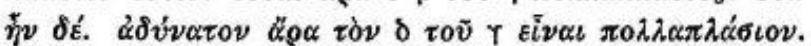

$\xi \pi l \mathrm{~W}$, perfossum in M. P. 152,7 vimd] $k \pi d \mathrm{~N}$. ${ }^{1 \beta} 1 \mathrm{\gamma}$

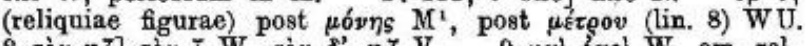

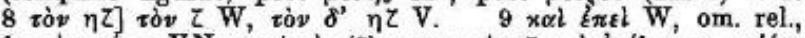

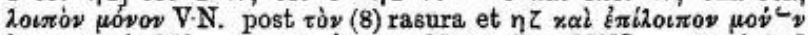

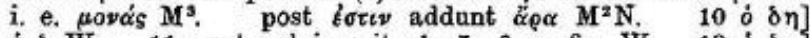
$\dot{\delta} \delta \mathrm{W} .11$ post $x \alpha i$ inserit is iz $i \theta$ ex fig. W. $12 \delta \delta \eta$ $\mathrm{N}$, iो $\delta \eta \mathrm{M}$, i) $\delta \mathrm{W} .18 \delta z \theta] \delta \theta Z \mathrm{~W}$. 1 post ôfor de lacuna 7 litt. W.

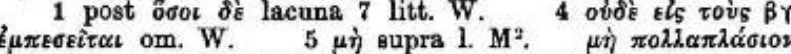
om. W. post oǔre habet $\pi$. $\lambda \lambda \alpha \pi \lambda \alpha$ supra lin. M. post

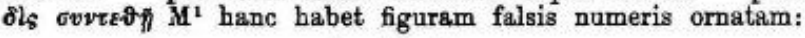

$$
|\gamma| \beta \mid \delta
$$

cui addit $M^{2}$ in margine figuram veriorem ex aequalibus lineis et ipsam compositam, veris tamen numeris instructam. aW deest figura (translata ad prot. 5). $14 \pi 0\llcorner\varepsilon i W .16 \tau \dot{W} v]$ tó libb.

13. Zứciopev in prot. 2. 
E quantos médios caiam em proporção entre os menores, tantos cairão em proporção também entre aqueles que tem a mesma razão ${ }^{12}$. E nenhum cairá entre os $\delta \zeta, \theta$, nem cairá entre os $\beta, \gamma$.

4. Caso um intervalo não múltiplo tenha sido duas vezes composto, o todo não será nem múltiplo, nem superparticular.

Seja, pois, o $\beta \gamma$ um intervalo não múltiplo, e fique posto, como o $\gamma$ para o $\beta$, o $\beta$ para o $\delta$. Digo que o $\delta$ não é nem múltiplo de $\gamma$ nem superparticular. Seja, pois, em primeiro lugar, o $\delta$ múltiplo de $\gamma$. Aprendemos, por conseguinte, que caso um intervalo duas vezes composto $9 \begin{array}{lll}9 & 6\end{array}$ faça um todo múltiplo, então este também é múltiplo ${ }^{13}$. Portanto, o $\beta$ será múltiplo de $\gamma$. Mas não era. É impossível, portanto, o $\delta$ ser múltiplo de $\gamma$.

${ }^{12}$ Provado em Elementos VIII. 8.

${ }^{13}$ Ver Proposição 2.

RBHM, Vol. 18, nº 36, p. 31-75, 2018 


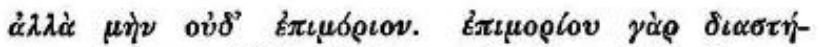

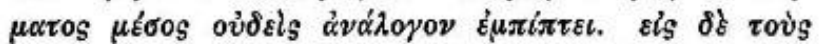

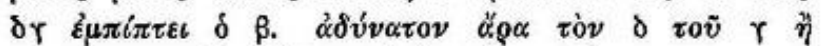

$\delta$

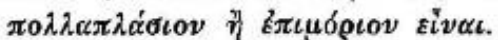

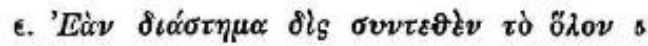

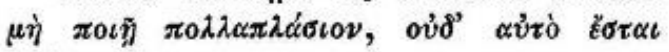
$\beta \quad \pi 0 \lambda \lambda \alpha \pi \lambda \dot{c} \sigma \iota \nu$.

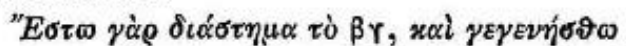

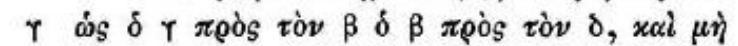

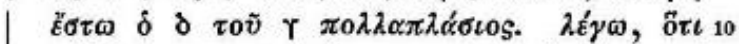

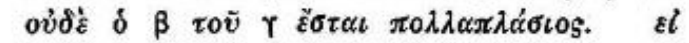

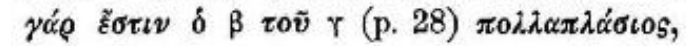

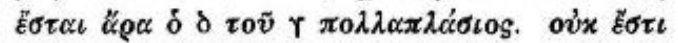

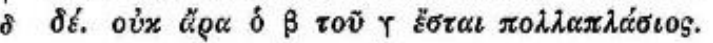

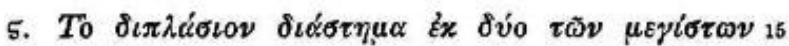

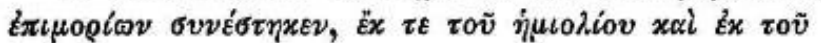

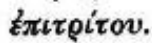

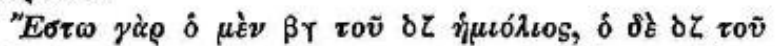

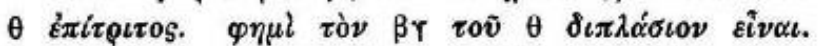

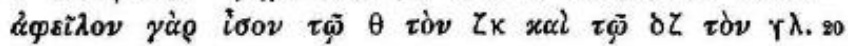

\footnotetext{
3 or VN, in ras. M, $\delta \gamma \theta$ W. $\tau \dot{\partial} \nu] \delta$ libb. $4 \pi . \pi 2 \alpha-$

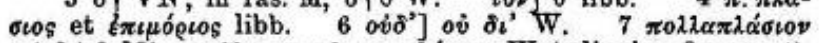

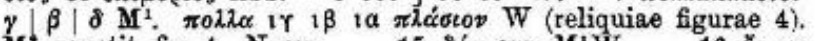
$\mathrm{M}^{2}$ repetit fig. $4, \mathrm{~N}$ om. 15 8vo om. M'W. 16 हैं $\tau \varepsilon$

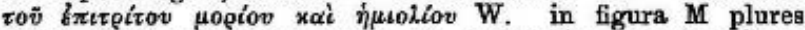
habet litteras (scriptas manu 3), sunt enim in prima linea partes indicatae $\delta$ et $\eta$ (hoc bis scr.), in altera linea inter $\delta$ et $\kappa$ scriptum $e$ (i. e. $\beta$ ). in $\mathrm{M}^{1} \mathrm{~W}$ nulla figurae vestigia. $20 z_{\kappa} M^{3} N^{2} U, z M^{1} V N, \beta W . \quad \gamma \lambda W N M^{3}, \gamma M^{1} V$.
}

20 obsis $d v . \quad \xi \mu \pi$. prot. 3. 
E tampouco superparticular. Pois nenhum médio em proporção cai de um intervalo superparticular ${ }^{14}$. Mas o $\beta$ cai em $\delta \gamma$. Portanto, é impossível o $\delta$ ser ou múltiplo de $\gamma$ ou superparticular.

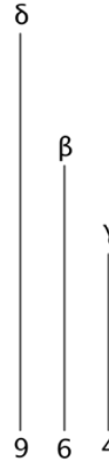

5. Caso um intervalo duas vezes composto não faça um todo múltiplo, nem mesmo o próprio será múltiplo.

Seja, pois, o $\beta \gamma$ um intervalo, e fique posto, como o $\gamma$ para o $\beta$, o $\beta$ para o $\delta$, e não seja o $\delta$ um múltiplo de $\gamma$. Digo que nem mesmo o $\beta$ será múltiplo de $\gamma$. Pois se o $\beta$ é múltiplo de $\gamma$, o $\delta$ será, portanto, múltiplo de $\gamma$. Mas não é. Portanto, o $\beta$ não será múltiplo de $\gamma$.

6. O intervalo duplo é composto de dois superparticulares maiores, tanto do hemiólico, quanto do epítrito.

Seja, pois, por um lado, o $\beta \gamma$ hemiólico de $\delta \zeta$, e de outro, o $\delta \zeta$ epítrito de $\theta$. Digo que o $\beta \gamma$ é duplo de $\theta$. Subtraí, pois, o $\zeta \kappa$ igual ao $\theta$, e o $\gamma \lambda<$ <igual> ao $\delta \zeta$.

\footnotetext{
${ }^{14}$ Ver Proposição 3.
} 


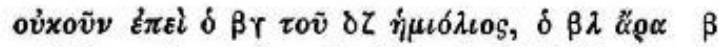

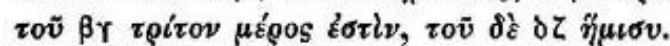

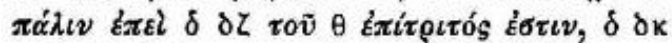

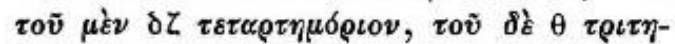
$5 \mu$ ó

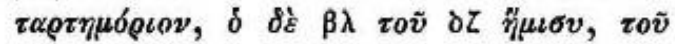

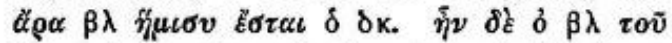

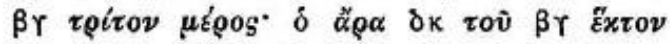

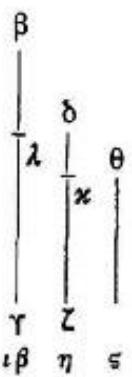

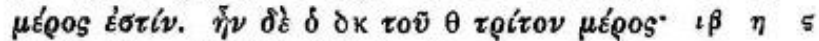

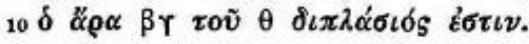

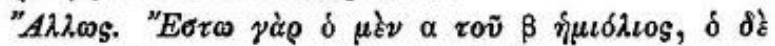

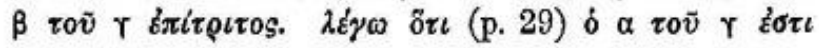

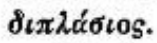

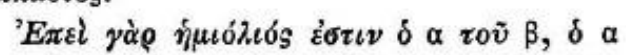

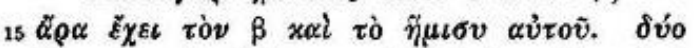

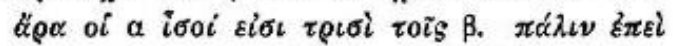

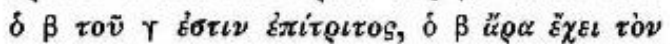

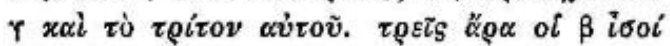

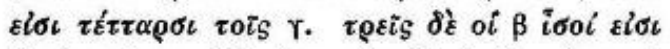

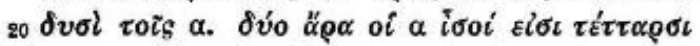

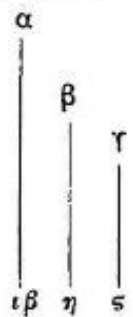

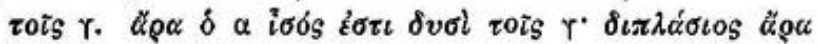
Ė $\sigma i \nu \delta \alpha \tau o \tilde{v} r$.

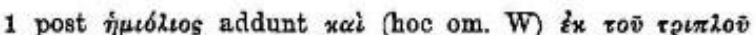

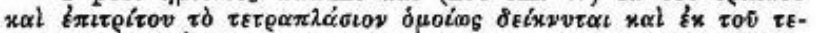

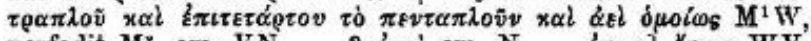

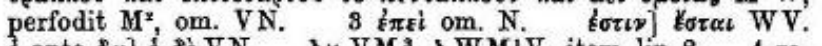

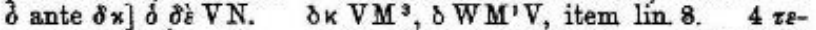

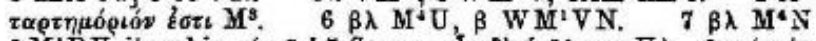

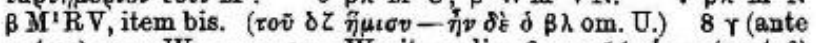
zoirov) om. W. $K$ om, W, item lin. 9.14 ó a (post $\beta$ )

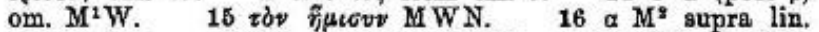

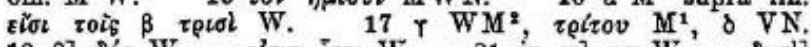

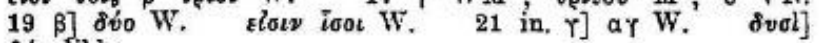
dío libb. 
Então, como o $\beta \gamma$ é hemiólico de $\delta \zeta$, o $\beta \lambda, \quad \beta$ portanto, é a terça parte do $\beta \gamma$, e a metade de $\delta \zeta$. De novo, como o $\delta \zeta$ é epítrito de $\theta$, o $\delta \kappa$ é, por um lado, uma quarta parte do $\delta \zeta$, e, por outro lado, uma terça parte de $\theta$. Então, como o $\delta \kappa$ é uma quarta parte do $\delta \zeta$, e o $\beta \lambda$ é a metade de $\delta \zeta$, o $\delta \kappa$ será, portanto, metade de $\beta \lambda$. E o $\beta \lambda$ era uma terça parte do $\beta \gamma$ : portanto, o $\delta \kappa$ é uma sexta parte do $\beta \gamma$. E o $\delta \kappa$ era uma terça parte de $\theta$ : portanto, o $\beta \gamma$ é duplo de $\theta$.

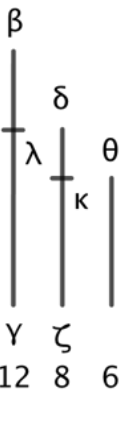

De um outro modo. Seja, pois, por um lado, o $\alpha$ hemiólico de $\beta$, e, por outro lado, o $\beta$ epítrito de $\gamma$. Digo que o $\alpha$ é duplo de $\gamma$.

Pois, como o $\alpha$ é hemiólico de $\beta$, o $\alpha$, portanto, contém o $\beta$ e sua metade. Dois $\alpha$, portanto, são iguais a três $\beta$. De novo, como o $\beta$ é epítrito de $\gamma$, o $\beta$, portanto, contém o $\gamma$ e seu terço. Três $\beta$, portanto, são iguais a quatro $\gamma$. E três $\beta$ são iguais a dois $\alpha$. Dois $\alpha$, portanto, são iguais a quatro $\gamma$. Portanto, o $\alpha$ é igual a dois $\gamma$. Portanto, $\alpha$ é o duplo de $\gamma$. 
III. Euclidis sectio eanonis.

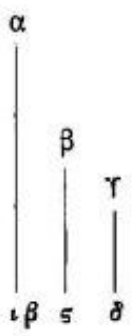

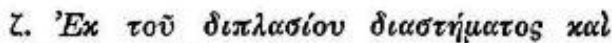
ทีแ

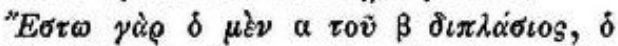

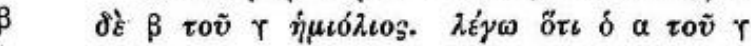

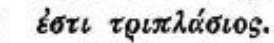

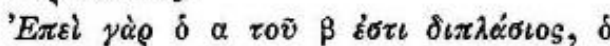

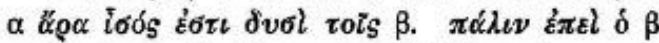

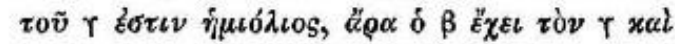

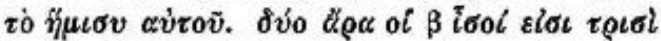

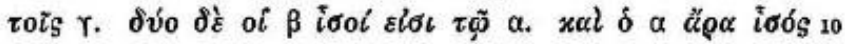

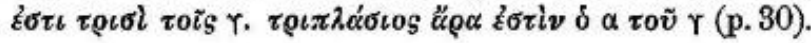

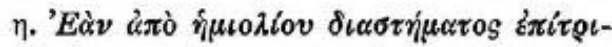

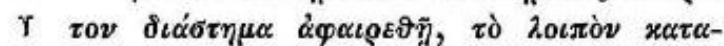

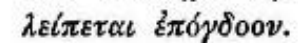

$\beta$

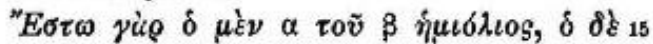

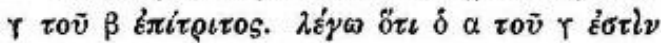

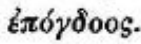

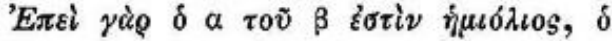

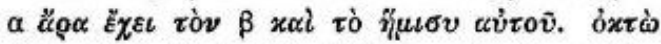

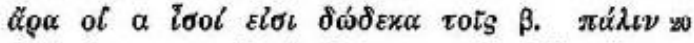

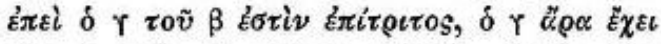

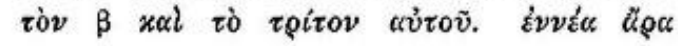

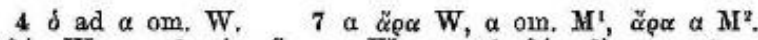

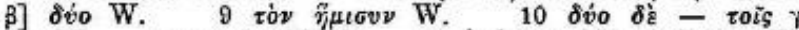

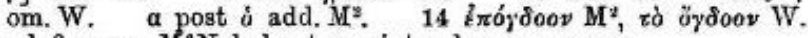
ad figuram $\mathrm{M}^{2} \mathrm{~N}$ habent ascriptos hos numeros:

$$
\begin{array}{ccc}
\vartheta & 5 & \eta \\
\eta & i \beta & 8 \\
o \beta & o \beta & o \beta .
\end{array}
$$

1 Hic aliam protasin insert Commentarius ad Ptol. p. 274, 1s, qua demonstratur praeter duplicem rationem ex superparticularibus componi multiplicem nullam. 


\section{De um intervalo duplo e um hemiólico} gera-se um intervalo triplo.

Seja, pois, por um lado, o $\alpha$ duplo de $\beta$, e, $\gamma$ por outro, o $\beta$ hemiólico de $\gamma$. Digo que o $\alpha$ é o triplo de $\gamma$.

Pois, como o $\alpha$ é duplo de $\beta$, o $\alpha$, portanto é igual a dois $\beta$. De novo, como o $\beta$ é hemiólico de $\gamma$, o $\beta$, portanto, contém o $\gamma$ e a sua metade.

Dois $\beta$, portanto, são iguais a três $\gamma$. E dois $\beta$ são iguais a $\alpha$. Também o $\alpha$ é igual a três $\gamma$. Portanto, o $\alpha$ é o triplo de $\gamma$.

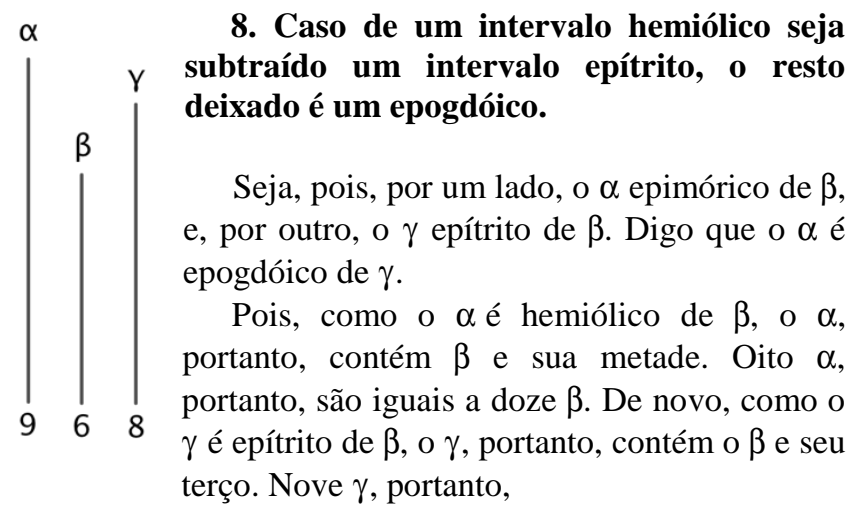




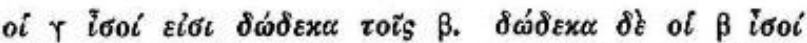

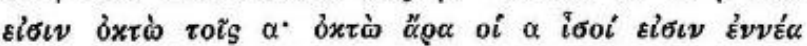

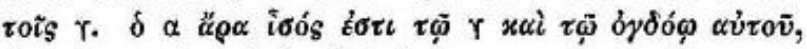

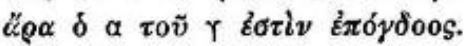

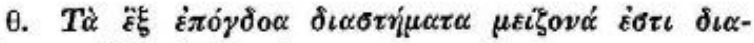

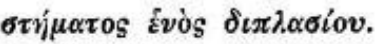

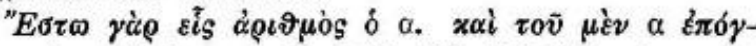

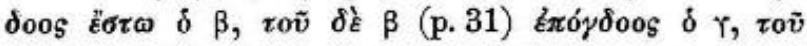

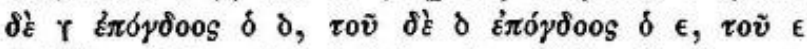

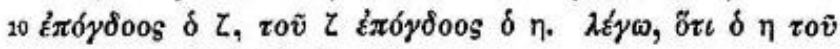

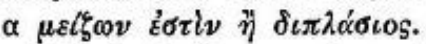

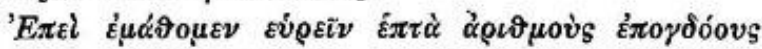

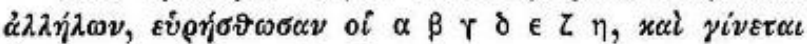

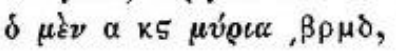

( $\vartheta 5 \eta$ medias ad lineas, $\eta \iota \beta, \vartheta$ imum ad finem positos).

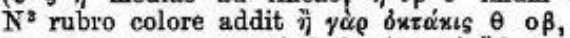

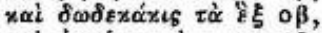

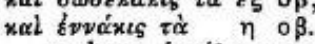

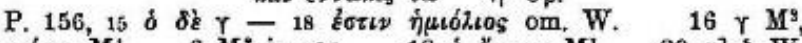

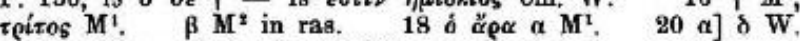

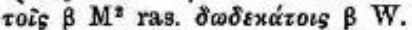

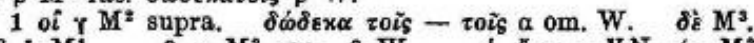
$2 \alpha] \delta M^{1}$. $3 \gamma M^{2}$ ras., $\beta W$. $\dot{\alpha} \rho \alpha \alpha \alpha$ V , (a M

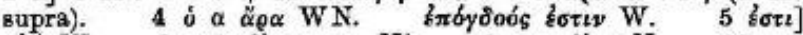

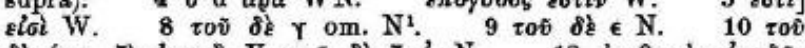

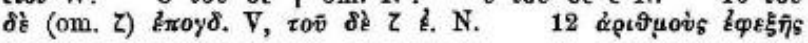
हn. $\mathrm{M}^{3} . \quad 14 \stackrel{\mathrm{x}}{M}$ libri, item in seqq. (*5 $\mathrm{M}^{2}$ ).

12 Heiberg Littergesch. Studien comparat El. 8, 2: ¿́oto-

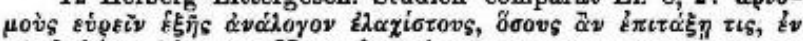

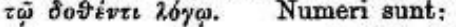

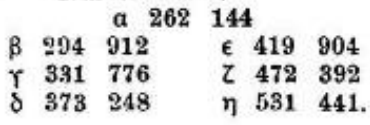


são iguais a doze $\beta$. E doze $\beta$ são iguais a oito $\alpha$ : portanto, oito $\alpha$ são iguais a nove $\gamma$. Portanto, o $\alpha$ é igual ao $\gamma$ e ao seu oitavo, portanto, o $\alpha$ é epogdóico de $\gamma$.

\section{Seis intervalos epogdóicos são maiores do que um intervalo duplo.}

Seja, pois, o $\alpha$ um número. $\mathrm{E}$, seja, por um lado, o $\beta$ epogdóico de $\alpha$, e, por outro, o $\gamma$ epogdóico de $\beta$, e o $\delta$ epogdóico de $\gamma$, e o $\varepsilon$ epogdóico de $\delta$, e o $\zeta$ epogdóico de $\varepsilon$, e o $\eta$ epogdóico de $\zeta$. Digo que o $\eta$ é maior do que o duplo de $\alpha$.

Como prendemos a achar sete números epogdóicos entre si, sejam achados os $\alpha, \beta, \gamma, \delta, \varepsilon, \zeta$, $\eta$, e torna-se o $\alpha$ 26 miríade $^{15} 2144$,

\footnotetext{
${ }^{15} \mathrm{O}$ substantivo feminino grego myrias (que dá origem a miríade, em português) tem valor numérico definido como dez mil. Sendo assim, deve-se ler as linhas onde este encontra-se antecedido por um número como uma multiplicação. Então, a expressão "26 miríade" significa 26 x 10.000. O sinal (vírgula) que segue na expressão (ver texto grego) representa a adição do número seguinte. Portanto, temos: $\alpha=26$ x $10.000+2144=262.144 ; \beta=$ $29 \times 10.000+4912=294.912$, e assim por diante.
}

RBHM, Vol. 18, nº 36, p. 31-75, 2018 


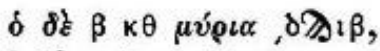

$\delta \delta \varepsilon \curlyvee \lambda_{\gamma} \mu v \dot{\rho} \iota \alpha, \alpha \psi 05$

$\delta$ dह $\delta \lambda z \mu v ́ \rho t \alpha, r c \mu \eta$,

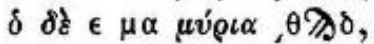

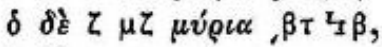

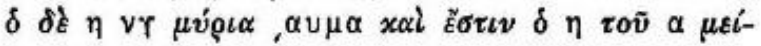

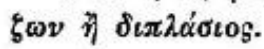

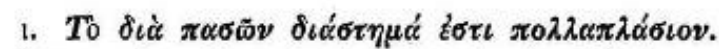

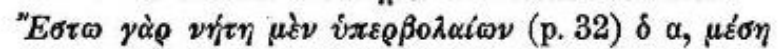

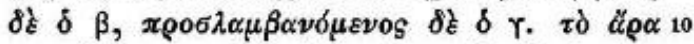

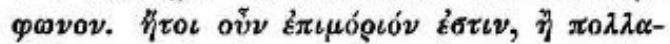

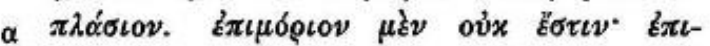

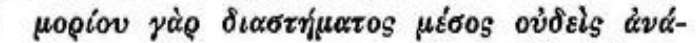

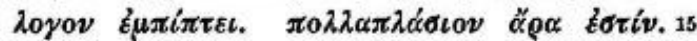

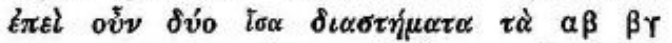

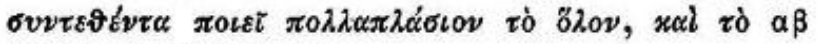

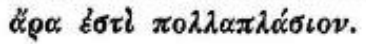

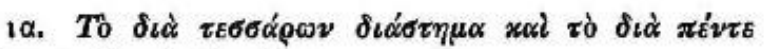

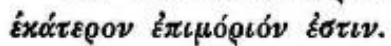

$12]\}, M, \tau W V N$. item in seqq. $2 \lambda r$ et $\alpha M^{2}$ 3 numeri $M^{2}, 4 \mu \alpha M^{2}$. D] $\psi W . \quad 6$ av $M^{2}$. $7 M^{1}$ habet reliquias figurae $|\alpha| \beta|\gamma| \delta|\varepsilon| \xi \mid \eta$. post $\delta$ i $2 \alpha^{2}-$

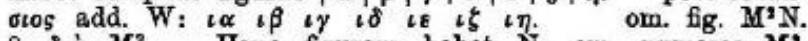
$8 \delta$ ¿่̀ $\mathbf{M}^{2}$ Hanc figuram habet $\mathbf{N}$, om. numeros $\mathbf{M}^{2}$.

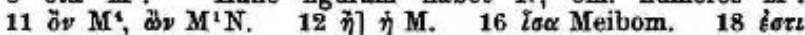
$\pi 0 \lambda \lambda \alpha \pi$ décotov et q. seq. - prot. 18 incl. om. W. alia manus ad mg. scribit $\lambda \varepsilon l \pi \varepsilon l$ के 8 . $191 \alpha \mathrm{V}, 1 \beta \mathrm{M}^{2}$, om. N. nec iam sequuntur protaseon numeri in codd. Figura vera in $\mathrm{N}$ apud prot. $6, M^{2}$ om.

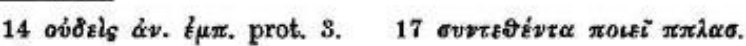
prot. 2. 
e o $\beta 29$ miríade 4912 ,

e o $\gamma 33$ miríade 1776 ,

e o $\delta 37$ miríade 3248 ,

e o $\varepsilon 41$ miríade 9904 ,

e o $\zeta 47$ miríade 2392 ,

e o $\eta 53$ miríade 1441, e o $\eta$ é maior do que o duplo do $\alpha$.

\section{O intervalo de oitava é múltiplo.}

Seja, pois, por um lado, o $\alpha$ nete hyperbolaion, e, por

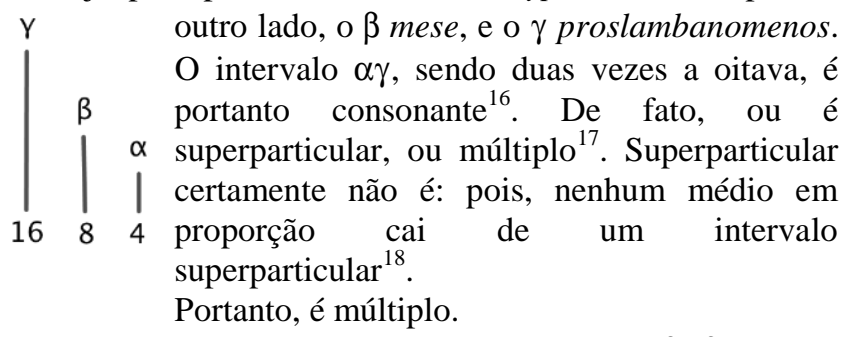

Como, de fato, dois intervalos iguais, os $\alpha \beta, \beta \gamma$, tendo sido compostos fazem um todo múltiplo, também o $\alpha \beta$, portanto, é múltiplo ${ }^{19}$.

\section{O intervalo de quarta e o de quinta, cada um dos dois, é superparticular.}

\footnotetext{
${ }^{16}$ A nete hyperbolaion é a nota mais alta do sistema harmônico grego, que é composto por duas oitavas. A oitava mais baixa é a proslambamenos, e a oitava mais alta, a nete. A localização delas no Cânone está representada na figura da Proposição 19. Cf. Barker, 2004, p. 199, n. 23.

${ }^{17}$ Conforme estabelecido no final da introdução.

${ }^{18}$ Ver Proposição 3.

${ }^{19}$ Ver Proposição 2.
}

RBHM, Vol. 18, n 36, p. 31-75, 2018 


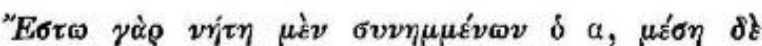

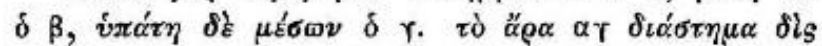

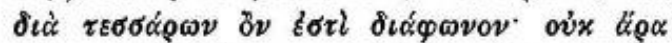

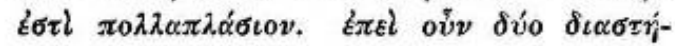

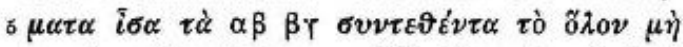

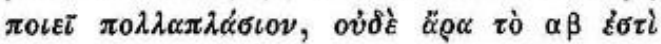

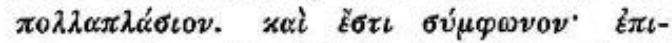

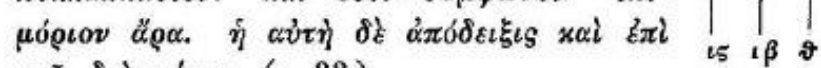
$\tau \circ \tilde{v} \delta \iota \grave{\alpha} \pi \varepsilon \dot{v} \tau \varepsilon$. (p. 33.)

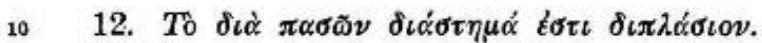

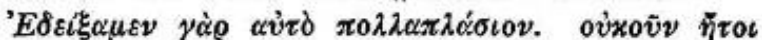

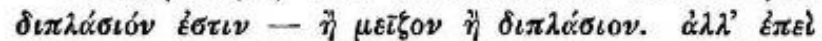

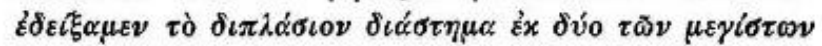

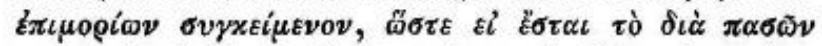

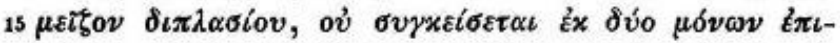

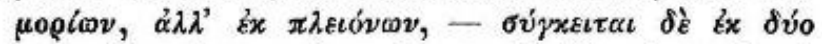

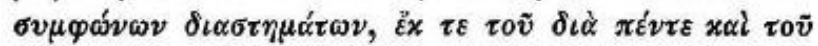

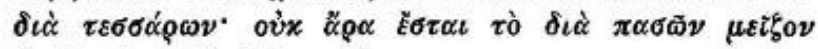

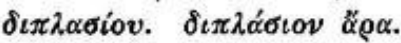

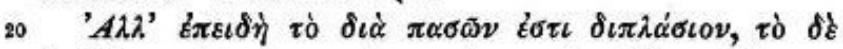

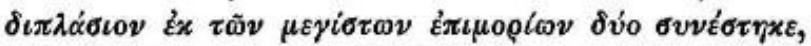

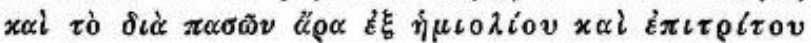

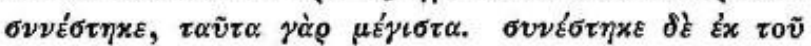

$2 \delta$ is $\mathrm{M}^{3}$ supra. $\quad 3$ ถึ $\nu \mathrm{M}^{2}$ ex numeros et partium signa, pergunt in linea. $11 \alpha v ̛$ rò]

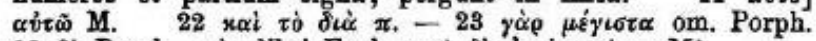

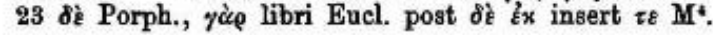

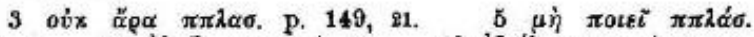

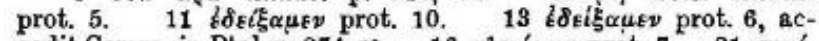

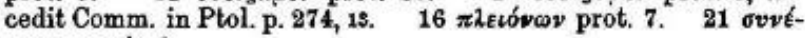

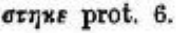


Seja, pois, tanto o $\alpha$ nete synemmenon, quanto o $\beta$ mese, e o $\gamma$ hypate meson ${ }^{20}$. O intervalo $\alpha \gamma$, sendo duas vezes a

quarta, é, portanto, dissonante: portanto, não é $\quad Y$ múltiplo. Como, de fato, os dois intervalos iguais, $\alpha \beta, \beta \gamma$, tendo sido compostos, não fazem um todo múltiplo, tampouco o $\alpha \beta$ é múltiplo $^{21}$. E é consonante: portanto, é superparticular. A mesma demonstração $\begin{array}{cccc}16 & 12 & 9\end{array}$ <vale> também para a quinta.

\section{O intervalo de oitava é duplo.}

Pois demonstramos que o mesmo é múltiplo ${ }^{22}$. Então, ou é duplo ou maior do que duplo. Mas como demonstramos, o intervalo duplo é composto de dois superparticulares maiores $^{23}$, de modo que se a oitava for maior do que um duplo, não será composta de só dois <intervalos>, mas de mais. E é composta de dois intervalos consonantes, da quinta e da quarta: portanto, a oitava não será maior do que um duplo. Portanto, é um duplo.

Mas, como a oitava é um duplo, e o duplo é construído sobre dois superparticulares maiores, também a oitava é construída, portanto, sobre um hemiólico e um epítrito, pois estes são maiores. E é construído sobre

\footnotetext{
${ }^{20}$ A nete synemmenon é uma quarta acima da mese, que, por sua vez, é uma quarta acima da hypate meson. Cf. Barker, 2004, p. 200, n. 27.

${ }^{21}$ Ver Proposição 5.

${ }^{22}$ Ver Proposição 10.

${ }^{23}$ Ver Proposição 6.
}

RBHM, Vol. 18, nº 36, p. 31-75, 2018 


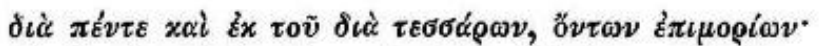

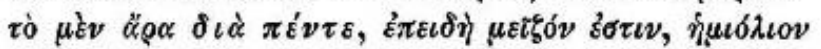

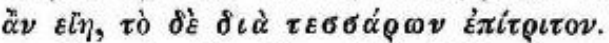

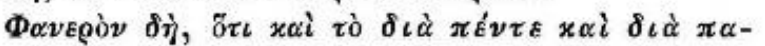

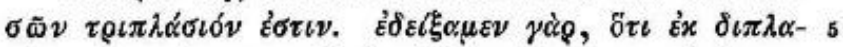

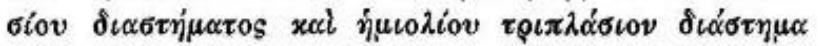

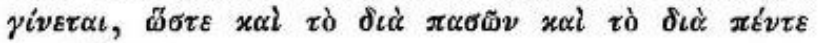
$\tau \varrho เ \pi \lambda \dot{\sigma} \sigma \iota \nu$.

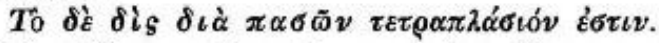

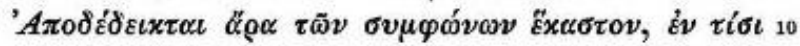

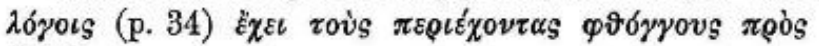
$\dot{\alpha} \lambda \lambda \dot{\lambda} \lambda$ ovs.

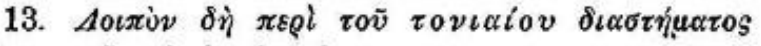

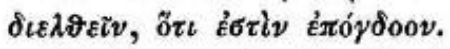

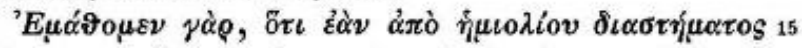

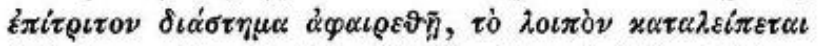

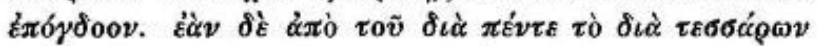

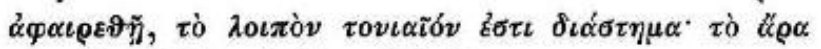

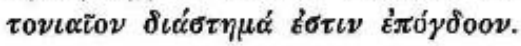

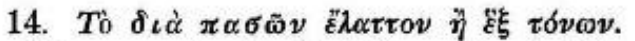

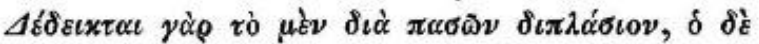

$3 z \pi t$ reírov N. $(4 \delta \dot{\eta}$ cf. Eucl. El. VII 36 med.

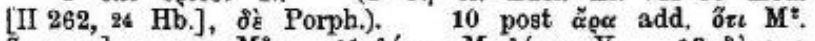

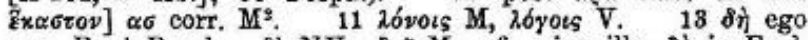
cum B et Porph., $\delta \dot{\varepsilon} \mathrm{NU}$, $\delta \varepsilon i \mathrm{M}$, cf. mira illa $\delta \grave{\eta}$ in Euel. Elem. 7, 2 et 36 (p. 192 et 262 H) 8,4 (282). 10, 3. (282).

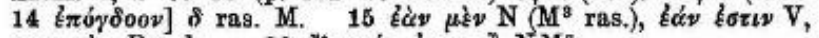

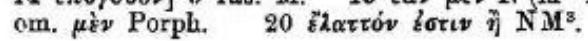

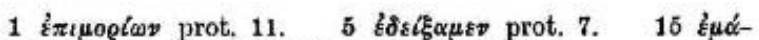

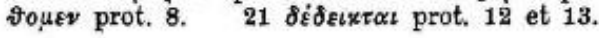


a quinta e a quarta, que são superparticulares: a quinta, por lado, é maior, portanto, será hemiólico, e a quarta, por outro lado, epítrito ${ }^{24}$.

É evidente, então, que tanto a quinta, quanto a oitava, são um <intervalo> triplo. Pois demonstramos, então, que de um intervalo duplo e de um hemiólico gera-se um intervalo triplo ${ }^{25}$, de modo que tanto a oitava, quanto a quinta, são um triplo.

E duas vezes a oitava é um <intervalo> quádruplo.

Está, portanto, demonstrado em quais razões cada uma das consonantes têm as notas contidas entre si.

13. Resta, então, considerar o intervalo de um tom, que é epogdóico.

Aprendemos, pois, que caso de um intervalo hemiólico seja subtraído um intervalo epítrito, o restante é um epogdóico ${ }^{26}$. E, caso da quinta seja subtraída a quarta, o restante é um intervalo de um tom: portanto, o intervalo de um tom é epogdóico.

\section{A oitava é menor do que seis tons.}

Pois está provado, tanto que a oitava é um duplo ${ }^{27}$,

${ }^{24}$ Ver Proposição 11

${ }^{25}$ Ver Proposição 7.

${ }^{26}$ Ver Proposição 8.

${ }^{27}$ Ver Proposição 12.

RBHM, Vol. 18, nº 36, p. 31-75, 2018 


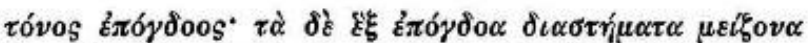

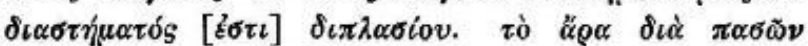

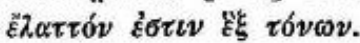

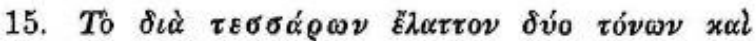

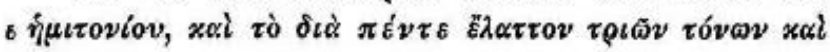

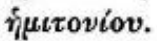

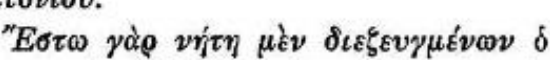

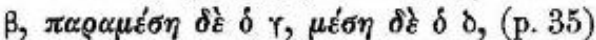

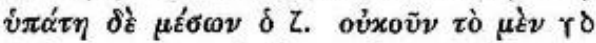

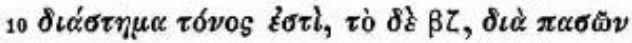

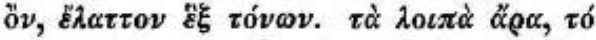

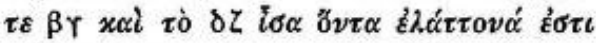

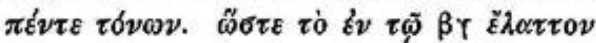

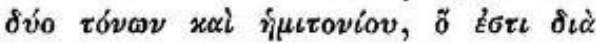

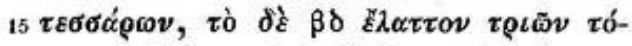

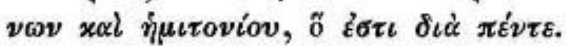

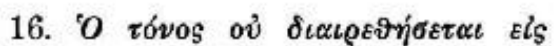

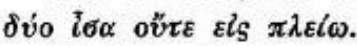

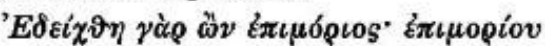

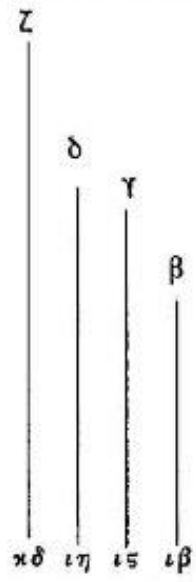

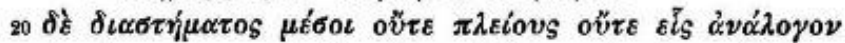

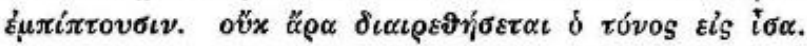

7 Hanc figuram habet $\mathrm{N}$ ad $\$ 6$, rubro ibi colore additur in marg. $\delta$ t⿳亠े $\pi \alpha \sigma \tilde{y} y \dot{\delta} \beta Z$. recto loco habent $\mathrm{M}^{2} \mathrm{~V}$ quattuor lineas aequales signatas $z$ o $\gamma \beta$ sine numeris. 11 ad tharrov add. Eoriv $\mathrm{M}^{4}$ supra. $14 \mathrm{M}^{1} \mathrm{VN}$, ô $\nu \mathrm{M}^{4}$. item lin. 16. 18 io $\alpha$ Jan, ǐovvs libb. (cf. 162, 14.) $\pi \lambda_{\varepsilon} l_{\omega}$ Porph., $\pi \lambda_{\varepsilon i o v s}$

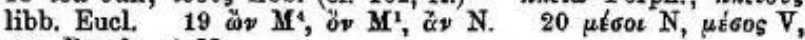
om. Porph. et M.

$1 \mu \varepsilon i \xi o v \alpha$ prot. $9.12 i \sigma \alpha, \operatorname{nam} \beta: \gamma=3: 4=\delta: \xi$.

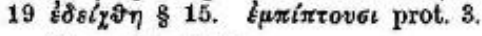

Mus. acript. ed. Jan.

11 
quanto o tom é um epogdóico ${ }^{28}$ : e seis intervalos epogdóicos são maiores do que um intervalo duplo ${ }^{29}$. Portanto, a oitava é menor do que seis tons.

15. A quarta é menor do que dois tons e um semiton, e a quinta é menor do que três tons e um semiton.

Seja, pois, tanto o $\beta$ nete diezeugmenon, quanto o $\gamma$ paramese, como o $\delta$ mese, e o $\zeta$ hypate meson ${ }^{30}$. Então, tanto o intervalo $\gamma \delta$ é um tom ${ }^{31}$, quanto o $\beta \zeta$, que é uma oitava, é menor do que seis tons ${ }^{32}$. Portanto, os restantes, tanto o $\beta \gamma$, quanto o $\delta \zeta$, que são iguais, são menores do que cinco tons. De modo que o <intervalo> em $\beta \gamma$, que é uma quarta, é menor do que dois tons e um semitom, e o $\beta \delta$, que é uma quinta, é menor do que três tons e um semitom.

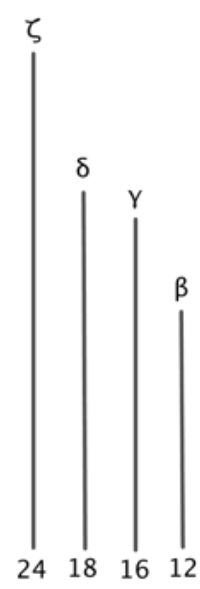

16. O tom não poderá ser dividido em dois nem em mais <intervalos> iguais.

Pois, foi provado ser superparticular ${ }^{33}$ : e nem um nem muitos médios em proporção caem de um intervalo superparticular $^{34}$. Portanto, o tom não poderá ser dividido em iguais.

${ }^{28}$ Ver Proposição 13.

${ }^{29}$ Ver Proposição 9.

${ }^{30}$ Nete diezeugmenon é uma quarta acima da paramese, que por sua vez é um tom acima da mese; hypate meson é uma quarta abaixo da mese e uma oitava abaixo da nete diezeugmenon. Nesse esquema, as quintas são aquelas da hypate até a paramese, e da mese até a nete. Barker, 2004, p. 202, n. 46.

${ }^{31} \mathrm{O}$ intervalo paramese-mese corresponde à diferença entre a quinta e a quarta. Ver Proposição 13.

${ }^{32}$ Ver Proposição 14.

${ }^{33}$ Ver Proposição 13

${ }^{34}$ Ver Proposição 3. 
z

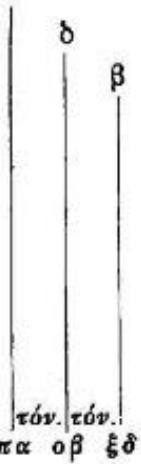

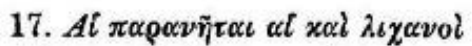

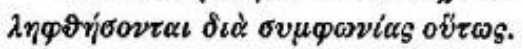

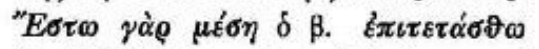

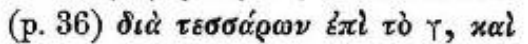

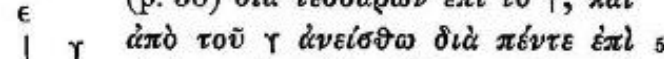

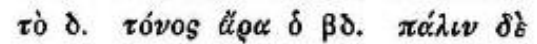

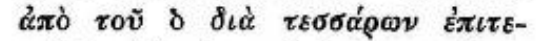

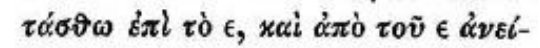

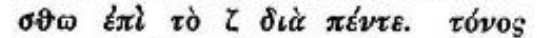

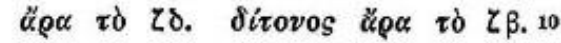

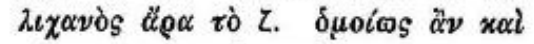

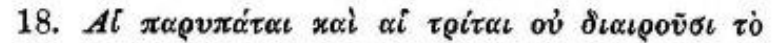

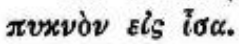

1 Exstant in $\mathrm{N}^{\mathrm{t}}$ ad prot. 7 hae quinque lineas diversa longitudine pariter inter se distantes, adsunt hi numeri hae-

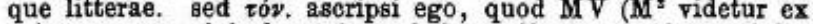
colore et marginis loco) haec habent diagrammatis vestigia:

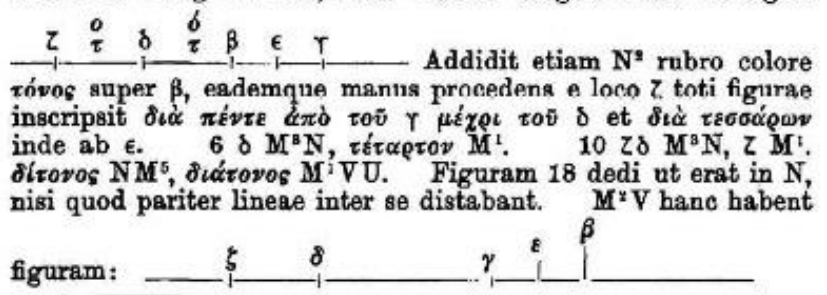

In $\$ 18$ hi sunt diagrammatis soni:

$\beta \bar{r}$ mese. a. la.

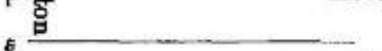

$\gamma \longrightarrow$ lichanos meson. g. sol.

$\delta$ - hypate meson. e. mi. 与을 lichan. byp. d. re. 


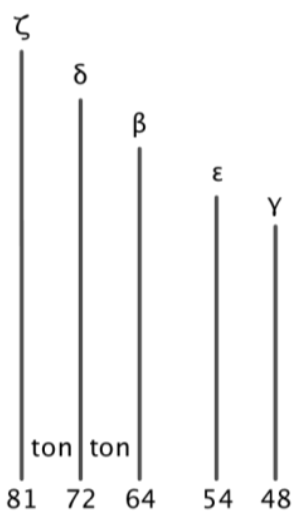

17. As paranetai e as lichanoi serão tomadas por meio de concordâncias.

Seja, pois, o $\beta$ mese. Fique estendida uma quarta até o $\gamma$, e de $\gamma$ fique reduzida uma quinta até o $\delta$. O $\beta \delta$, portanto, é um tom ${ }^{35}$. De novo, fique estendida uma quarta, de $\delta$ até $\varepsilon$, e fique reduzida uma quinta, de $\varepsilon$ até $\zeta$. O $\zeta \delta$, portanto, é um tom. O $\zeta \beta$, portanto, é um dítono. $\mathrm{O} \zeta$, portanto, é lichanos ${ }^{36}$. $\mathrm{E}$ do mesmo modo são tomadas as paranetai.

18. As parypatai e as tritai não dividem o pyknon em <intervalos> iguais.

${ }^{35}$ Ver Proposição 13.

${ }^{36} \mathrm{O}$ lichanos está dois tons abaixo da mese.

RBHM, Vol. 18, n 36, p. 31-75, 2018 


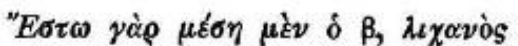

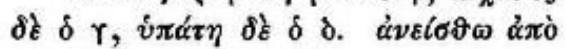

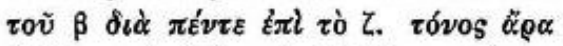

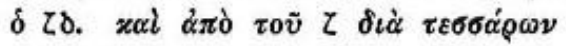
亏 દ̇ं

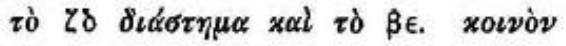

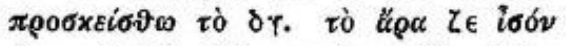

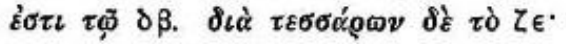

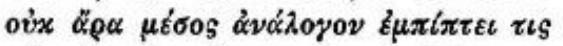

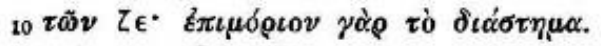

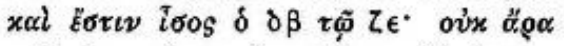

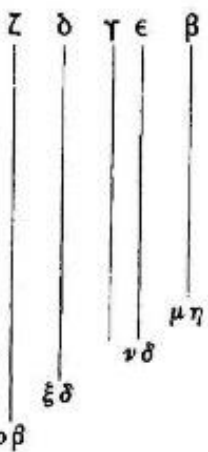

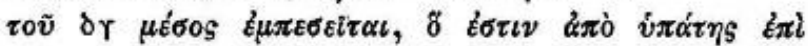

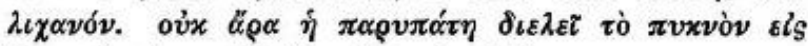

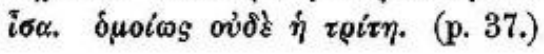

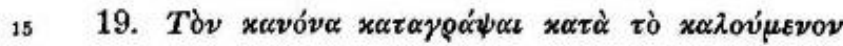
$\alpha \dot{\alpha} \mu \tau \tau \dot{\alpha} \beta \beta$

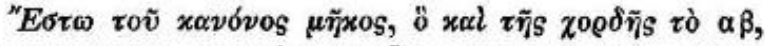

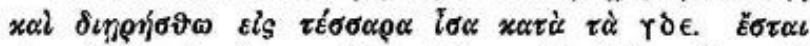

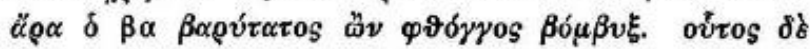

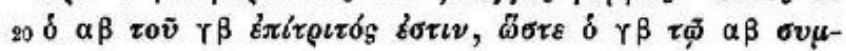

6 xal $\mathrm{M}^{2}$ supra. $\beta \epsilon$ ego, $\gamma \in$ libri. ( $\beta \epsilon$ tonus est, quia

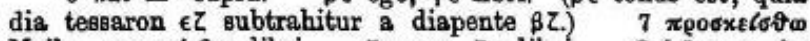

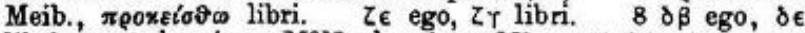

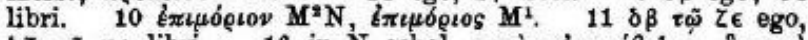

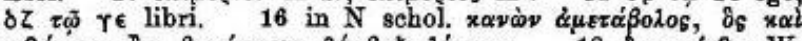

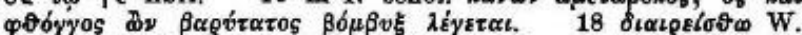

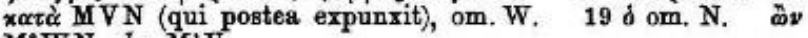
$\mathbf{M}^{3} \mathrm{WN}, \dot{\omega} \nu \mathrm{M}^{1} \mathrm{~V}$.

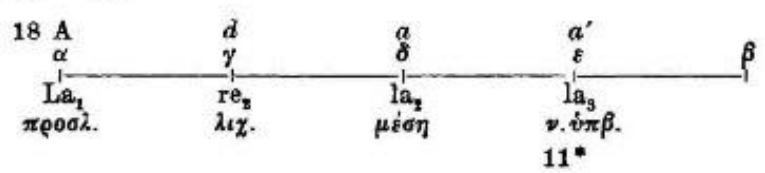


Seja, pois, tanto o $\beta$ mese, quanto o $\gamma$ lichanos, e o $\delta$ hypate. Fique reduzida uma quinta, de $\beta$ até $\zeta$. $O \zeta \delta$, portanto, é um tom. E, fique estendida uma quarta, de $\zeta$ até $\varepsilon$. Portanto, o intervalo $\zeta \delta$, e também o $\beta \varepsilon$, é um tom. Fique adicionado o $\delta \gamma$ comum. $\mathrm{O} \zeta \varepsilon$, portanto, é igual ao $\delta \beta$. E o $\zeta \varepsilon$ é uma quarta: portanto, nenhum médio em proporção cai de $\zeta \varepsilon$ : pois o intervalo é superparticular ${ }^{37}$. E o $\delta \beta$ é igual ao $\zeta \varepsilon$ :

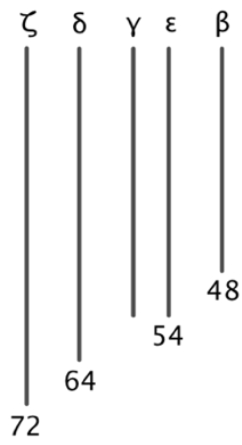
portanto, nenhum médio cai de $\gamma \delta$, que é o <intervalo> de hypates até lichanos. Portanto, a parypate não dividirá a pykton em <intervalos> iguais. Do mesmo modo, tampouco a trite.

19. Descrever o cânone segundo a chamada escala imutável.

Seja um comprimento do cânone, o mesmo da corda $\alpha \beta$, e fique dividido em quatro <intervalos> iguais, segundo os $\gamma, \delta$, e $\varepsilon$. Portanto, sendo o $\beta \alpha$ mais grave, será a nota mais baixa. E este $\alpha \beta$ é epítrito de $\gamma \beta$, pois o $\gamma \beta$ será consonante

\footnotetext{
${ }^{37}$ Assim como se faz na música em nossos dias, pode-se ler a expressão como "uma quarta acima". Denota-se um sentido ascendente quando o comprimento do segmento de corda que vibra (e emite som) torna-se menor, de modo que um som mais agudo do que outro é considerado mais alto do que este.
}

RBHM, Vol. 18, nº 36, p. 31-75, 2018 


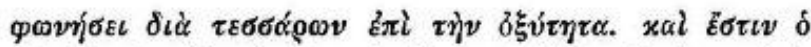

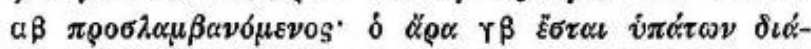

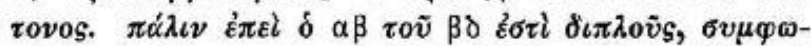

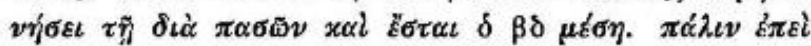

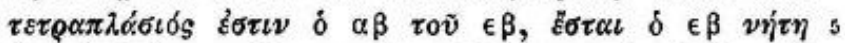

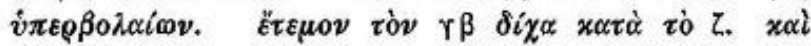

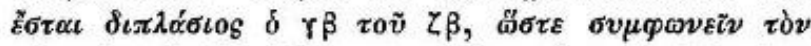

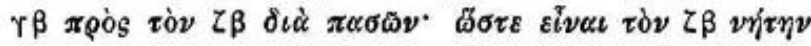

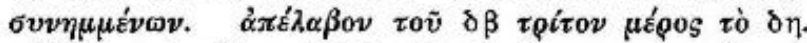

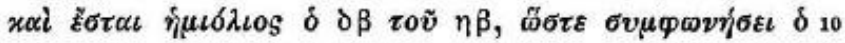

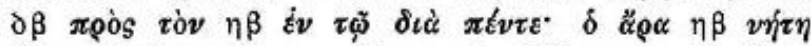

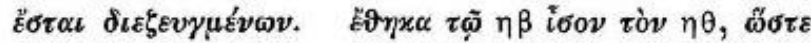

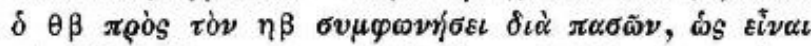

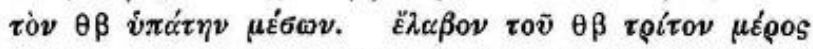

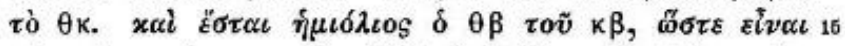

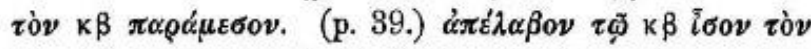

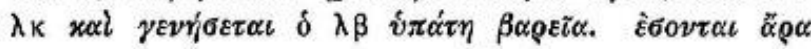

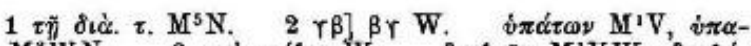

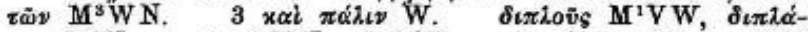

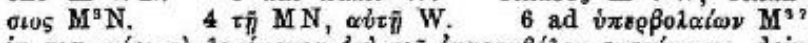

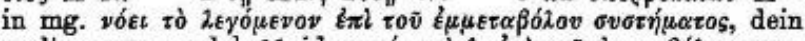

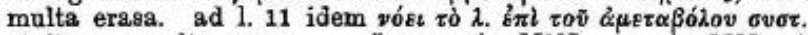

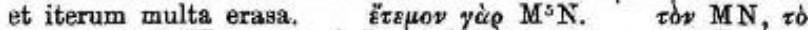

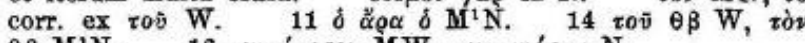
$\theta \beta \mathrm{M}^{2} \mathrm{~N} . \quad 16 \pi \alpha \rho \alpha \dot{\alpha \varepsilon \sigma \sigma o \nu} \mathrm{MW}, \pi \alpha \rho \alpha \mu \xi_{\sigma} \eta \nu \mathrm{N}$.

P. 165,1 . $\varepsilon \sigma \tau \omega \tau \varepsilon s$ ego. 3 hoc habet diagramma $\mathrm{M}^{2} \mathrm{mg}$.

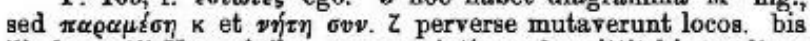
illud repetit $V$ nominibus non ascriptis, sed omittit bis $\lambda$, altero loco etiam $\eta$. WN omittunt figurum.

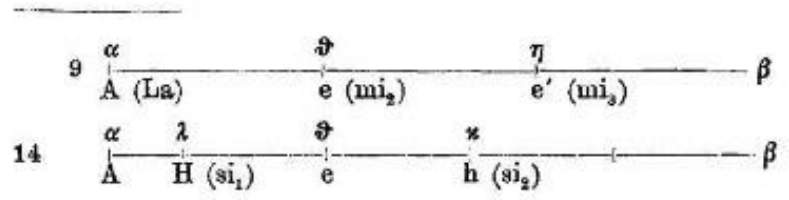


com o $\alpha \beta$ de quarta mais aguda ${ }^{38}$. E o $\alpha \beta$ é proslambanomenos: portanto, o $\gamma \beta$ será hypaton diatônico $^{39}$. De novo, como o $\alpha \beta$ é duplo de $\beta \gamma$, será consonante de oitava, e o $\beta \gamma$ será mese. De novo, como o $\alpha \beta$ é quádruplo de $\varepsilon \beta$, o $\varepsilon \beta$ será nete hyperbolaion. Cortei o $\gamma \beta$ em dois, segundo o $\zeta$. E o $\gamma \beta$ será duplo de $\zeta \beta$, de modo que o $\gamma \beta$ é consonante com o $\zeta \beta$ de oitava: de modo que o $\zeta \beta$ será nete synemmenon. Tomei de $\delta \beta$ uma terça parte, o $\delta \eta$, e o $\delta \beta$ será hemiólico de $\eta \beta$, de modo que o $\delta \beta$ será consonante com o $\eta \beta$ de quinta: portanto, o $\eta \beta$ será nete diezeugmenon. Pus o $\eta \theta$ igual ao $\eta \beta$, de modo que o $\theta \beta$ será consonante com o $\eta \beta$ de oitava, de modo a ser o $\theta \beta$ hypate meson. Tomei de $\theta \beta$ uma terça parte, o $\theta \kappa$. E o $\theta \beta$ será hemiólico de $\kappa \beta$, de modo a ser o $\kappa \beta$ parameson. Tomei de $\kappa \beta$ um igual ao $\lambda \kappa$, e o $\lambda \beta$ formará

\footnotetext{
${ }^{38}$ Assim como se faz na música em nossos dias, pode-se ler a expressão como "uma quarta acima”. Denota-se um sentido ascendente quando o comprimento do segmento de corda que vibra (e emite som) torna-se menor, de modo que um som mais agudo do que outro é considerado mais alto do que este.

${ }^{39}$ Isto é, será um tom abaixo da hypate meson.
}

RBHM, Vol. 18, nº 36, p. 31-75, 2018 


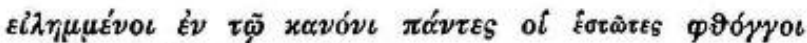

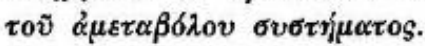

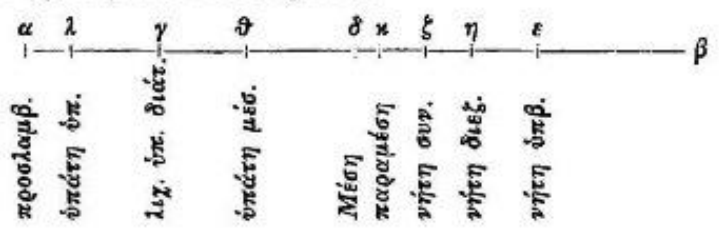

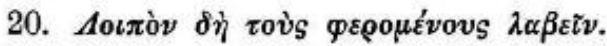

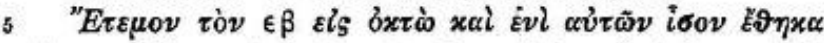
$\tau \grave{v} v \epsilon \mu$,

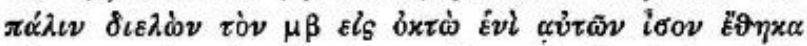

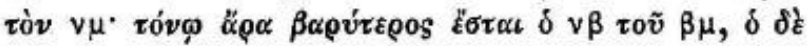

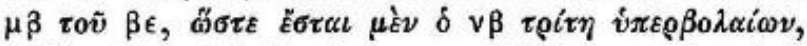

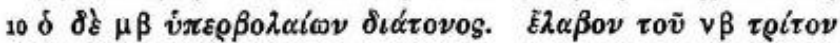

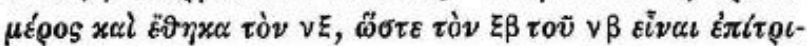

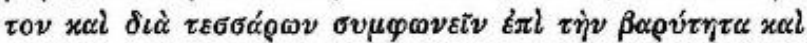

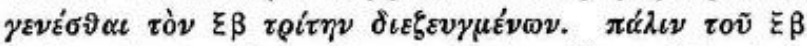

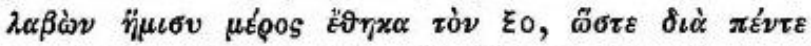

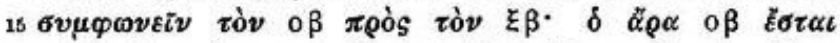

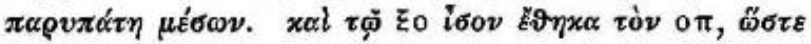

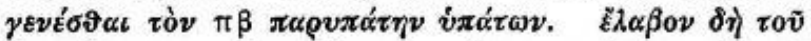

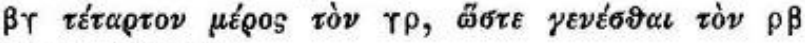

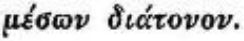

$4 \delta \dot{\eta}$ ego, $\delta \xi i$ libri, ef, p. 34, 4. $5 \tau \dot{\partial} v$ W, $\tau \dot{\partial} \mathrm{MN}$.

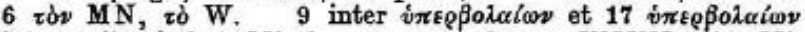

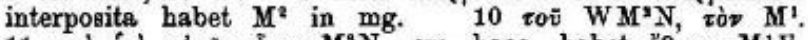

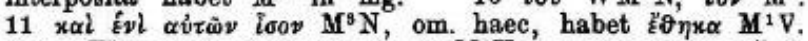

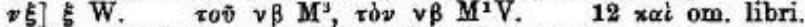

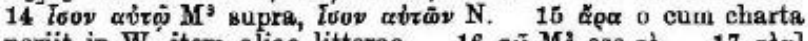
periit in W, item aliae litterae. $16 \tau \tilde{\omega} \mathrm{M}^{3}$ esc $\left.\tau \dot{0} .17 \tau \dot{\delta} \nu\right]$

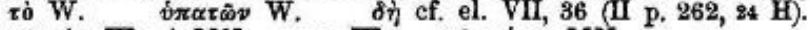

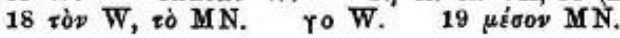


uma hypate grave. Portanto, ficarão descritas sobre o cânone todas as notas fixadas da escala imutável.

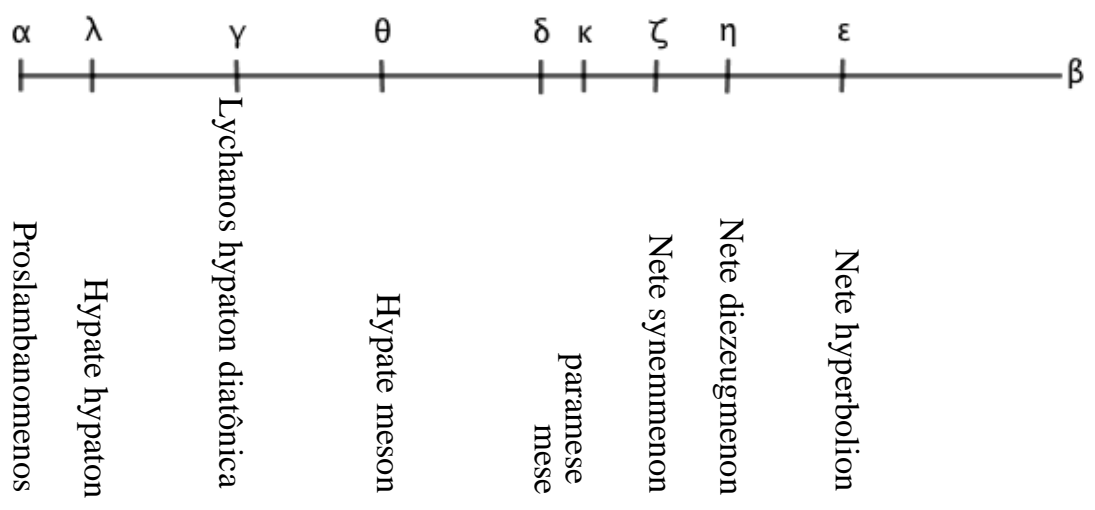

20. Resta, por fim, encontrar as <notas> móveis.

Cortei o $\varepsilon \beta$ em oito, e, igual a um destes, pus o $\varepsilon \mu$ de modo que o $\mu \beta$ seja epogdóico de $\varepsilon \beta$. E, de novo, dividindo o $\mu \beta$ em oito, igual a um destes pus o $v \mu$ : portanto, o v $\beta$ será um tom mais grave do que o $\beta \mu$, e o $\mu \beta$ do que o $\beta \varepsilon$, de modo que tanto o $v \beta$ será trite hyperbolaion, quanto o $\mu \beta$ hyperbolaion diatônico. Tomei do v $\beta$ uma terça parte e <igual a um destes> pus o $v \xi$, de modo que o $\xi \beta$ será epítrito de $v \beta$ e consonante de quarta mais grave, e o $\xi \beta$ trite diezeugmenon. De novo, tomei de $\xi \beta$ uma metade, e <igual a ela> pus o $\xi$ o, de modo a ser o o $\beta$ consonante com o $\xi \beta$ de quinta: portanto, o o $\beta$ será parypate meson. E pus o o $\pi$ igual ao $\xi_{0}$, de modo a ser o $\pi \beta$ parypate hypaton. Tomei de $\beta \gamma$ uma quarta parte, o $\gamma \rho$, de modo a ser o $\rho \beta$ meson diatônica. 
III. Euclidis sectio canonis. § 20.

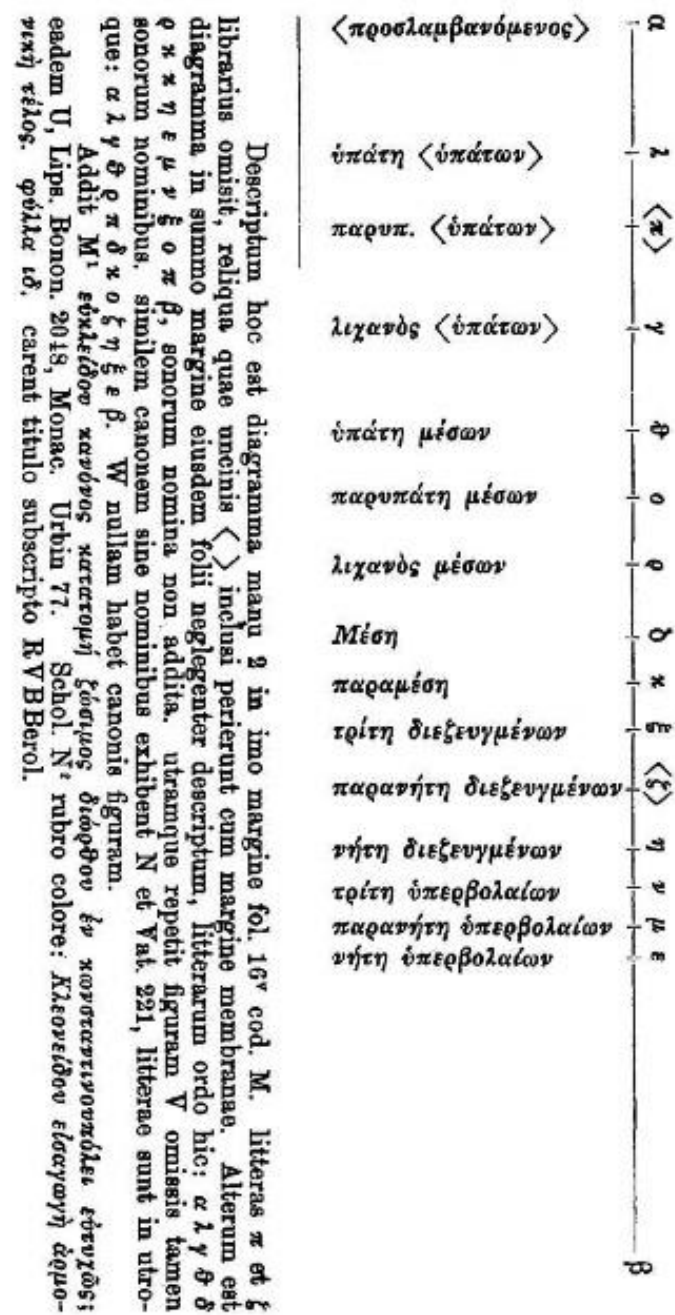




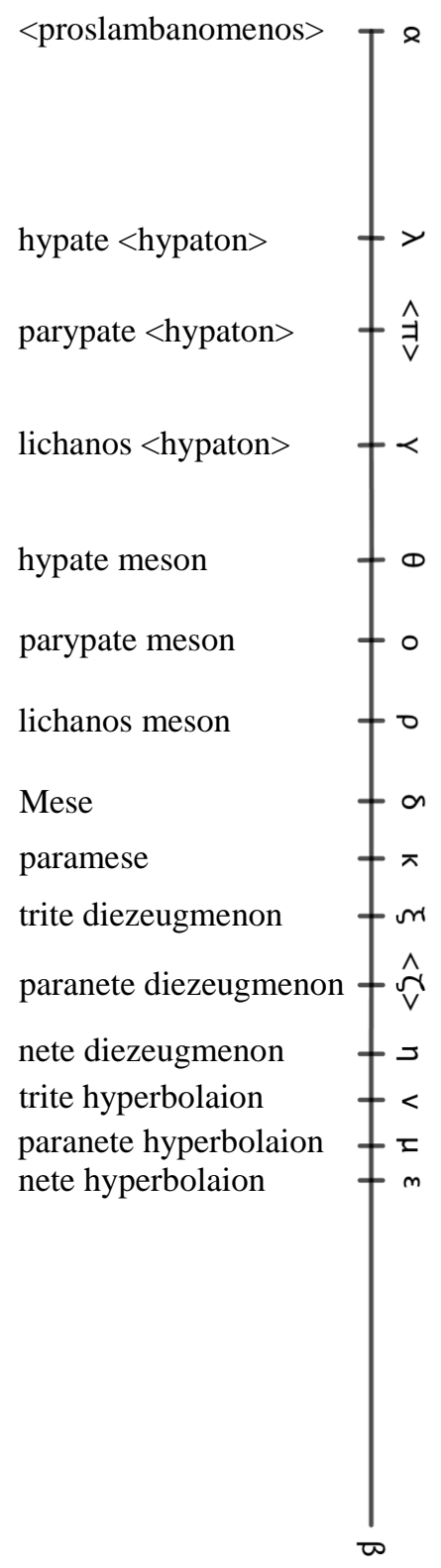

RBHM, Vol. 18, nº 36, p. 31-75, 2018 